\title{
Comorbidities of COPD
}

\author{
Arnaud Cavaillès', Graziella Brinchault-Rabin², Adrien Dixmier³, \\ François Goupil ${ }^{4}$, Christophe Gut-Gobert', Sylvain Marchand-Adam ${ }^{6,7}$, \\ Jean-Claude Meurice ${ }^{8}$, Hugues Morel ${ }^{9}$, Christine Person-Tacnet ${ }^{10}$, \\ Christophe Leroyer ${ }^{5,11}$ and Patrice Diot ${ }^{7,12}$
}

\begin{abstract}
Affiliations: 'Dept of Pulmonology, Institut du Thorax, CHU de Nantes, Nantes, ${ }^{2}$ Dept of Pulmonology, Hôpital Pontchaillou, Rennes, ${ }^{11}$ Université Européenne de Bretagne, UBO, EA3878 (GETBO) IFR 148, Rennes, ${ }^{3}$ Dept of Pulmonology, CHR d'Orléans, Orléans, ${ }^{4}$ Dept of Pulmonology, Centre Hospitalier Le Mans, Le Mans, ${ }^{5}$ Dept of Internal Medicine and Pulmonology, University Hospital La Cavale Blanche, Brest, 'Universite François Rabelais de Tours, INSERM U1100, Tours, ${ }^{12}$ Universite François Rabelais de Tours, EA6305, Tours, ${ }^{7}$ Dept of Pulmonology, CHU de Tours, Tours, ${ }^{8}$ Dept of Pulmonology, Centre hospitalier de l'Université de Poitiers, Poitiers, ${ }^{9}$ Dept of Pulmonology, Hôpital Broussais Hospital, Saint-Malo, and ${ }^{10}$ Dept of Pulmonology, CHU Angers, Angers, France.
\end{abstract}

Correspondence: A. Cavaillès, Dept of Pulmonology, Institute du Thorax, CHU de Nantes, Boulevard Jacques Monod, 44093 Nantes Cedex 1, France. E-mail: arnaud.cavailles@chu-nantes.fr

ABSTRACT By 2020, chronic obstructive pulmonary disease (COPD) will be the third cause of mortality. Extrapulmonary comorbidities influence the prognosis of patients with COPD. Tobacco smoking is a common risk factor for many comorbidities, including coronary heart disease, heart failure and lung cancer. Comorbidities such as pulmonary artery disease and malnutrition are directly caused by COPD, whereas others, such as systemic venous thromboembolism, anxiety, depression, osteoporosis, obesity, metabolic syndrome, diabetes, sleep disturbance and anaemia, have no evident physiopathological relationship with COPD. The common ground between most of these extrapulmonary manifestations is chronic systemic inflammation.

All of these diseases potentiate the morbidity of COPD, leading to increased hospitalisations and healthcare costs. They can frequently cause death, independently of respiratory failure. Comorbidities make the management of COPD difficult and need to be evaluated and treated adequately.

0 @ERSpublications

Extrapulmonary comorbidities are common in COPD and influence prognosis; we propose an exhaustive comorbidities review http://ow.ly/o5Uqu

\section{Introduction}

All the studies conducted agree in predicting that both the morbidity and mortality burden of chronic obstructive pulmonary disease (COPD) is rising. By 2020, COPD is projected to cause over 6 million deaths annually worldwide, thus becoming the third leading cause of death in the world [1]. The general ageing of the world's population is reinforcing this trend, partly due to the fact that the prevalence is higher in age groups $>50$ years (the average age of patients with COPD is 70 years $[2,3]$ ), and partly because incidence remains high in the elderly. For a male aged $>55$ years who is free from COPD, the estimated risk of developing COPD over the next 40 years is $24 \%$ [4].

Our general understanding of the disease has greatly improved over the past 10 years. Epidemiological studies and large clinical trials have helped us to understand the importance of comorbidities [5, 6]. Greater

Received: Dec 282012 | Accepted after revision: Feb 222013

Support statement: The study was supported by Novartis Pharma AG (Paris, France).

Conflict of interest: Disclosures can be found alongside the online version of this article at err.ersjournals.com

Provenance: Submitted article, peer reviewed.

Copyright OERS 2013. ERR articles are open access and distributed under the terms of the Creative Commons Attribution Non-Commercial Licence 3.0. 
understanding of the pathophysiology of COPD, focused on the concept of systemic inflammation, has also helped to explain the high frequency of major comorbidities (such as cardiovascular, skeletal and nutritional disorders) in addition to coexisting conditions that one would naturally expect due to the patients' advanced age and due to shared risk factors. This article reviews the major comorbidities encountered in patients with COPD.

\section{Cardiovascular comorbidities}

Heart disease and systemic and pulmonary vascular diseases in COPD

Vascular and heart diseases are among the most important comorbidities observed in COPD, because they have a direct impact on patient survival. The pathophysiological mechanisms underlying the vascular alterations observed in COPD appear to be mainly mediated by endothelial dysfunction and coagulopathy.

\section{Endothelial dysfunction and COPD}

The systemic inflammation observed in COPD seems to be the key determinant for the development of pulmonary [7] and systemic [8] endothelial dysfunction, although the precise pathophysiological mechanisms are unknown. Other factors could be involved in maintaining endothelial integrity, such as circulating endothelial progenitor cells (CEPCs). The number of CEPCs appears to be reduced in the systemic circulation and increased in the pulmonary circulation of patients with COPD $[7,9]$.

\section{Coagulopathy and COPD}

The systemic inflammation present in COPD appears to induce a "pro-coagulant" state. In the basal state, COPD patients exhibit abnormally high levels of tissue factor (tissue factor pro-coagulant activity) and Factor VIIa [10], and their fibrin clots are resistant to lysis [11]. After $2 \mathrm{~h}$ of artificial hypoxaemia, compared to non-hypoxic controls, COPD patients have abnormally elevated levels of circulating thrombin-antithrombin complex and prothrombin activation fragments, with a parallel elevation in interleukin (IL)-6 [12].

It was recently discovered that coagulation is altered in patients with COPD: tissue factor pro-coagulant activity and circulating levels of thrombin-antithrombin complex are higher than in control subjects, constituting a prothrombotic and pro-inflammatory state that increases the risk of stroke [10]. An electron microscopy study showed that fibrin clots isolated from the plasma of COPD patients are denser and more resistant to lysis than those from control subjects with an equivalent circulating fibrinogen concentration [11]. The same study showed that the fibrin clots from COPD patients became similar to those from subjects without COPD after 3 months of simvastatin treatment.

\section{Systemic venous thromboembolism and COPD}

The three factors of Virchow's triad are observed in COPD (systemic venous endothelial dysfunction, coagulopathy and venous stasis due to a physical inactivity), which explains their predisposition to venous thromboembolism (VTE). During COPD exacerbations, VTE is found in 3-29\% of cases [13, 14]. There are no specific clinical, biological or radiological signs indicative of VTE, but it should be suspected during COPD exacerbation in the presence of chest pain or syncope, or a fall in arterial carbon dioxide tension in a patient who is usually hypercapnic. VTE during a COPD exacerbation prolongs hospitalisation by 4.4 days and increases the 1-year mortality rate by $30 \%$ [14]. Failure to diagnose VTE and to institute suitable anticoagulant therapy increases the death rate by $25 \%$ during hospitalisation.

\section{Pulmonary artery disease and COPD: pulmonary hypertension}

Pulmonary artery remodelling is observed early in COPD and leads to pulmonary hypertension (PH). This remodelling is the consequence of endothelial dysfunction and coagulopathy, but also of lung-specific mechanisms, such as hypoxic vasoconstriction, destruction of the pulmonary capillary bed by emphysema, smoking-induced inflammatory infiltration of the vascular wall, and shear stress due to redistribution of the blood flow [15]. $\mathrm{PH}$ is defined by a mean pulmonary artery pressure $(\mathrm{mPpa})>25 \mathrm{mmHg}$ associated with a pulmonary artery occlusion pressure $<15 \mathrm{mmHg}$ and by a pulmonary vascular resistance (PVR) $>3$ Wood units. The prevalence of $\mathrm{PH}$ in COPD is $\sim 5-40 \%[15,16]$. But moderate and severe $\mathrm{PH}$ (defined by an $\mathrm{m} P$ pa $>35 \mathrm{mmHg}$ and $>45 \mathrm{mmHg}$, respectively) only account for $\sim 5 \%$ of cases in hospital-based patient series. The presence of $\mathrm{PH}$ in COPD worsens gas exchange and dyspnoea, and predisposes to right ventricular (RV) dysfunction and peripheral oedema. It is also associated with higher mortality [17-19].

$\mathrm{PH}$ should be suspected in a COPD patient with dyspnoea, desaturation during the 6-min walk test or a disproportionate reduction in the diffusing capacity of the lung for carbon monoxide relative to the severity of the obstruction, or clinical or biological (brain natriuretic peptide) signs of RV dysfunction, not explained by either left ventricular failure or a loud second heart sound in the pulmonic area. 
On echocardiography, a high maximum tricuspid regurgitation velocity (TRmax $>3.5 \mathrm{~m} \cdot \mathrm{s}^{-1}$ ) is suggestive of $\mathrm{PH}$, but TRmax cannot be evaluated in one-third of COPD patients due to the low echogenicity of emphysematous lungs [20]. Cardiac catheterisation remains the only examination that can be used to confirm the diagnosis of $\mathrm{PH}$ and assess its severity. The presence of $\mathrm{PH}$ has little impact on the therapeutic management of COPD. Only long-term oxygen therapy has been shown to be beneficial, which stabilises $\mathrm{PH}$ in certain patients with COPD [21].

\section{Coronary heart disease and COPD}

Epidemiological association

Coronary heart disease and COPD share the same main risk factor, i.e. smoking. The strong epidemiological link between the two diseases is therefore unsurprising. The presence of symptoms of simple chronic bronchitis increases the risk of death due to a coronary event by $50 \%$. The impact of obstructive airway disease, defined by a decrease in the ratio of forced expiratory volume in $1 \mathrm{~s}$ (FEV1) to forced vital capacity (FVC), is less clear-cut, as it only increases the risk of a coronary event by $30 \%$. However, for every $10 \%$ decrease in FEV1, all-cause mortality increases by $14 \%$, cardiovascular mortality increases by $28 \%$ and the frequency of non-fatal coronary events increases by $20 \%$. The link between COPD and coronary heart disease is independent of any other confounding coronary risk factors, namely smoking status, cholesterol, systemic hypertension and body mass index (BMI) [22].

\section{Shared pathophysiological mechanisms}

Coronary heart disease and COPD are both inflammatory diseases and both involve clotting abnormalities. This phenomenon has long been known for coronary heart disease, and was demonstrated much more recently in COPD (see previously).

In coronary heart disease, the activation of immune cells in the atheromatous plaque induces the production of cytokines such as interferon- $\gamma$, IL-1, tumour necrosis factor (TNF)- $\alpha$, IL- 6 and acute-phase inflammatory proteins (fibrinogen, C-reactive protein (CRP) and amyloid protein) [23]. The same mediators are involved in the inflammatory reaction observed in the bronchus in COPD. In addition to these shared pathophysiological determinants, the presence of COPD could contribute to the development of cardiovascular disease through hypoxia, systemic inflammation and oxidative stress [24], and through impaired vasodilatory capacity, as has been shown in the brachial arteries [25].

\section{Coexistence of COPD and coronary heart disease worsens the prognosis of both diseases}

Coronary heart disease often goes unrecognised in COPD. A retrospective study of the medical records of 897 COPD patients treated between 2000 and 2003 was conducted in Akershus University Hospital (Oslo, Norway) [26]. The records of 827 (92\%) patients included an ECG. Sequelae of myocardial infarction were found on the ECGs of 229 (27.6\%) patients, yet only 30\% of these patients had a recognised history of myocardial infarction. Follow-up of the cohort until 2005 revealed the negative impact of a high ECG-based cardiac infarction injury score on their survival.

COPD is associated with a systemic inflammatory response and, in particular, with CRP elevation, the concentration of which increases with the severity of the bronchial obstruction. This systemic inflammatory reaction might play a role in the increased coronary risk in patients with COPD [27]. The effect of COPD medication on cardiovascular events is not yet completely clear. The analysis of the data collected during the TORCH (Towards a Revolution in COPD Health) study showed no increase in cardiovascular events in patients with moderate-to-severe COPD receiving salmeterol alone or in combination with oral steroid therapy [28]. The possibility that tiotropium provokes cardiovascular adverse effects continues to be raised [29], with a relationship between the dose placed in the inhaler and the risk of adverse effects having recently been suggested [30].

Heart failure and COPD

Heart failure and COPD are diseases with very similar risk factors, particularly through the role of smoking, that share pathophysiological mechanisms, such as inflammation and skeletal muscle alterations. This explains the frequent coexistence of the two conditions [31], the underestimation of which can lead to delayed diagnosis, given the similarity of the symptoms and to treatment inefficacy.

\section{Heart failure in patients with COPD}

In a recent study, transthoracic echocardiography was prospectively performed in 342 COPD patients 3 months after their first exacerbation. Significant cardiac alterations were present in $64 \%$ of patients: $27 \%$ left- and/or $48 \%$ right-heart disorders. In $63 \%$ of these patients, cardiac disease was not known [32]. 
A meta-analysis of 12 analysable studies, published in 2006, in which heart failure was defined as a combination of typical clinical symptoms and a left ventricular ejection fraction of $<50 \%$, confirmed that the prevalence of the coexistence of these conditions varies with the stability of the COPD [33]. The prevalence among patients experiencing an exacerbation was as high as $46 \%$ versus $3.8-16 \%$ in those with stable disease. The importance of this combination was confirmed in a cohort study including $>45000$ patients with COPD and a sex- and age-matched healthy population of the same size, whose end-points were hospitalisation and cardiovascular mortality rates over a follow-up period of almost 3 years [34]. In terms of relative risk, after adjustment for confounding factors and pre-existing cardiovascular disease, heart failure was the leading cause of hospitalisation and death during the study period. The correlation was stronger in subjects aged $<65$ years. These results were confirmed in a more recent study on a smaller population (1927 patients) recently diagnosed with COPD and followed for over 5 years [35]. After adjustment for age and sex, the risk of heart failure and death was significantly higher in patients with COPD than in healthy subjects from a database compiled from the general population.

Impact of COPD on heart failure

There are few data on the impact of COPD in patients with heart failure. One of the first studies followed 800 patients with heart failure for 5 years and showed that survival was significantly lower in the group with concomitant COPD. Recent studies on this relationship have corroborated this initial analysis. The studies based on the Norwegian Heart Failure Registry, including 4132 patients with heart failure from 22 cardiology centres, followed for nearly 8 years, demonstrated a significantly higher proportion of deaths in patients with concomitant COPD (32.6\% versus 37.0\%; $\mathrm{p}=0.03$ ) [36]. At baseline, $\beta$-blocker therapy was less frequent among patients in the COPD group than in COPD-free patients with identical cardiopathy. This is regularly reported in the literature and should be specifically addressed, given the major role of $\beta$-blockers in improving the prognosis of heart failure. There were no data on COPD severity in this cohort, but the results of a less recent study on a smaller number of patients with heart failure are particularly interesting because they took into account the Global Initiative for Chronic Obstructive Lung Disease (GOLD) grades of patients with concomitant COPD [37]. Indeed, whereas COPD status was not associated with a significant increase in mortality over the $14.2 \pm 8.8$ months of follow-up, the survival curves for the various stages of COPD severity revealed that survival among patients with GOLD grades 3 or 4 was significantly lower.

COPD therefore appears to be a truly independent risk factor for death in compromised heart failure patients, and the coexistence of COPD can delay the diagnosis of heart failure. The other causes may be related to the increased risk of non-cardiac death in heart failure patients, infection, or the risk that the coexistence of COPD and heart failure worsens right ventricular dysfunction. The role of $\beta$-blockers must also be taken into account. They are known to improve the survival of patients with heart failure, yet are commonly underused in patients with COPD, due to concerns that they will worsen the airway obstruction. Patients are therefore denied the full benefit of heart failure treatments. The use of non-selective $\beta$-blockers, which have similar affinity for $\beta 1$ and $\beta 2$ receptors, is generally accompanied by a reduction in FEV1, but this is well tolerated in most cases [38]. Switching to a cardioselective $\beta$-blocker improves spirometric values, without affecting the left ventricular ejection fraction or New York Heart Association functional class, enabling a better cardiac prognosis without the risk of compromising respiratory function.

The prevalence of heart failure increases with age: eight cases out of 1000 persons for a 50 -year-old and $10 \%$ after the age of 80 years [39]. Heart failure has been demonstrated to worsen the prognosis of COPD [40].

\section{Lung cancer}

Epidemiology

Several epidemiological studies have demonstrated a link between COPD and lung cancer. The prevalence of COPD among lung cancer patients ranges from $40 \%$ to $70 \%$, depending on the study [41, 42]. The prevalence of COPD of GOLD grade 2 or higher in a cohort of patients with lung cancer was $50 \%$, compared to $8 \%$ in a cohort of smokers without lung cancer (OR 11.6). The annual incidence of lung cancer was at least four times higher in a cohort of patients with COPD than in the general population [43]. While MAnnino et al. [44] demonstrated a risk proportional to the severity of the airway obstruction, DE TORRES et al. [45] very recently showed that the least severe stages of COPD are associated with a greater risk for developing lung cancer.

Patients with COPD at the time of lung cancer diagnosis have a poorer prognosis [43]: 3-year survival in the COPD-lung cancer group was $15 \%$ versus $26 \%$ in the lung cancer without COPD group (fig. 1). Similarly, an increase in death due to lung cancer was found in nonsmokers with emphysema (HR 1.66) and in nonsmokers with both emphysema and chronic bronchitis (HR 2.44) [46]. 


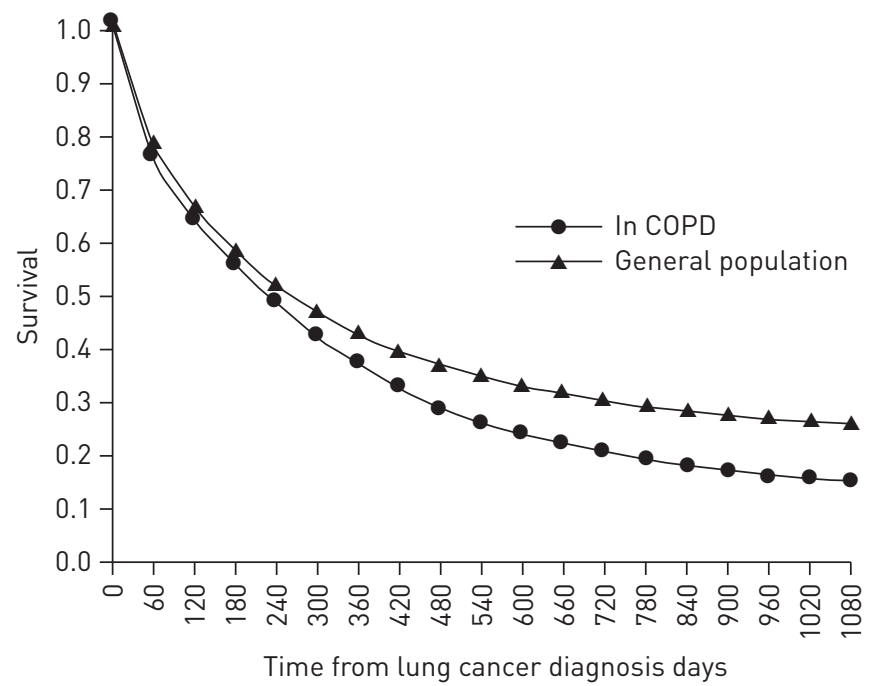

FIGURE 13 -year survival of lung cancer patients in the general population and in those with a prior diagnosis of chronic obstructive pulmonary disease (COPD). COPD is a negative predictor of survival in lung cancer patients. Reproduced from [43] with permission from the publisher.

\section{Pathophysiology}

The mechanisms that predispose COPD patients to lung cancer are not yet fully elucidated [47]. There are currently two main hypotheses.

\section{Shared genetic links that predispose to both diseases}

A genetic risk factor common to both of these diseases, combined with the risk related to smoking, was first suggested in 1977 by COHEN et al. [48]. Very recently, genome analyses of patients with COPD and lung cancer have shown susceptibility loci common to both diseases on several chromosomes (e.g. 15q25, 4q31 and 6p21) [49]. Many susceptibility genes shared by both diseases have been identified, with roles in detoxification, extracellular matrix remodelling (particularly matrix metalloproteinases (MMPs) such as MMP1), DNA repair, cell proliferation and tumour suppression [50]. Conversely, two genetic variants of the $4 \mathrm{q} 31$ locus appear to confer protection against COPD and lung cancer in smokers [51]. Finally, a role for epigenetic changes common to the development of lung cancer and COPD has also been suggested. For example, modifications such as DNA methylation, deacetylation of histone proteins and protein phosphorylation have been shown to be involved in the pathogenesis of both diseases [52].

\section{The role of chronic inflammation}

Epithelial-to-mesenchymal transition (EMT), in which cells with an epithelial phenotype acquire a mesenchymal phenotype, is known to have an important role in carcinogenesis [52]. Bronchial inflammation itself promotes such EMT. Many factors are shared by these two diseases, such as activation of transforming growth factor- $\beta$ and of the receptor tyrosine kinase/RaS pathway. Similarly, the transcription factor nuclear factor $(\mathrm{NF})-\kappa \mathrm{B}$ is a key protein in the pathogenesis and development of COPD, enhancing the release of pro-inflammatory mediators. Genes that regulate NF- $\kappa B$ have also been implicated in tumour development and metastasis. In addition, inhibitors of NF- $\kappa \mathrm{B}$ have been shown to improve the efficacy of first-line therapy in lung cancer patients with COPD [53].

\section{Screening}

To our knowledge, there is no specific recommendation to screen for lung cancer in patients with COPD. Recent data from the American National Lung Screening Trial [54] showed a 20\% reduction in death due to lung cancer in the group screened using computed tomography compared to the group screened by radiography, among smokers or former smokers aged between 55 years and 74 years with a smoking history of $\geqslant 30$ pack-years. The patients' lung function was not reported in the trial. These epidemiological data suggest that targeted lung cancer screening for COPD patients could be worthwhile. The value of targeted screening for patients with severe disease (GOLD grade 3 or 4) could be investigated in a clinical trial.

A respiratory workup is recommended at the time of diagnosis of localised or locally advanced lung cancer, including at least lung function tests [55]. It is important because COPD severity has an impact on treatment. The local or regional treatment chosen (lung resection, external beam radiotherapy or radiofrequency ablation) depends, in part, on the patient's lung function.

There is no recommendation to screen for the presence of airway obstruction in metastatic lung cancer. The issue is whether COPD treatment would improve the quality of life or even the survival of the patient. 
Severe COPD, especially at the stage of chronic respiratory failure, can affect performance status. Performance status must be maintained for chemotherapy to be initiated and is one of the key factors when deciding which cytolytic therapy to use.

\section{Preventing lung cancer in COPD}

Smoking cessation is the cornerstone of COPD management. It is the main way of stopping the progression of COPD and of minimising the risk of developing lung cancer.

Pharmacological treatments (nicotine replacement therapy, bupropion and varenicline) and cognitive behavioural therapy have been shown to be effective in increasing the chances of successful cessation for COPD patients [56-58]. Two retrospective cohort studies suggest that inhaled corticosteroids may be protective against lung cancer $[59,60]$. A dose-response relationship has been observed between exposure to inhaled corticosteroids and the reduction in the risk of lung cancer. Only high doses of inhaled corticosteroids appear to significantly decrease the risk of lung cancer. Their protective effect is assumed to be based on their anti-inflammatory action. In animal models, they reduce the risk of oncogenesis in bronchopulmonary tissues [61].

A role for physical activity in cancer prevention has also been postulated. Using multivariate analysis of a cohort followed for over 12 years, SPRAGUE et al. [62] demonstrated that the risk of developing lung cancer was $45 \%$ lower in one-third of the population (4831 subjects) with the highest levels of physical activity than in the third with the lowest levels of physical activity, particularly among the subpopulation of active smokers. The authors did not evaluate the subjects' lung function, so no conclusions can, as yet, be drawn on the benefit of physical activity in the prevention of lung cancer in the COPD subpopulation. To our knowledge, there are no other data, particularly on the effect of a long-term exercise retraining programme on the incidence of lung cancer in COPD patients.

\section{Anxiety and depression disorders}

Anxiety is defined by a feeling of indefinable insecurity, which characterises the psychological component of anxiety disorders. Depression, which comes from the Latin depressio meaning "press down", denotes an illness for some or a syndrome for others, whose central manifestation is a mental state characterised by marked lassitude, reduced self-esteem and pessimism. These disorders are common in COPD, anxiety and dyspnoea are closely linked, and depression is more frequent in COPD than in other chronic diseases.

One study suggested that the first hospitalisation for COPD occurs sooner in patients with concomitant anxiety and/or depression. One hypothesis is that dyspnoea might be perceived more intensely and earlier in these patients [63].

Similarly, proven airway obstruction is associated with a higher frequency of generalised anxiety disorder or panic disorder [64]. Depression affects between $20 \%$ and $60 \%$ of COPD patients depending on the study, COPD stage and the scale used [65-67]. The mortality and readmission rate among anxious and/or depressive COPD patients increases during the 30 days following hospitalisation [68]. The presence of depression has prognostic value, as shown in a study in COPD patients hospitalised for exacerbation [69]. Mortality following a COPD exacerbation was greater among the depressive patients. A simple questionnaire has been validated as a rapid screening instrument for anxiety and depressive disorders [70].

Depression is also a common comorbidity in the elderly population. Its prevalence is $1-5 \%$ among ambulatory patients, 13\% among institutionalised patients [71] and $40 \%$ in patients with respiratory failure. YOANNES et al. [72] showed that the rate of depression in a group of 96 elderly COPD patients was significantly higher than in healthy or otherwise disabled elderly subjects.

The Hospital Anxiety and Depression (HAD) scale is an easy-to-use self-report questionnaire that can be helpful in routine practice. It has 14 questions in total and takes about $10 \mathrm{~min}$ to complete [73]. The "anxiety" score is obtained by adding the scores from questions 1, 4, 6, 8, 10, 12 and 14. The "depression" score is obtained by adding the scores from questions $2,3,5,7,9,11$ and 13 . For each item, a score strictly $>10$ indicates an abnormal state of anxiety and/or a high probability of depression. The scale has also been validated in French. However, doctor-patient relationship is essential to assess the psychological impact of the disorder.

Occasionally, medical therapy is necessary. Antidepressants alter the perception of symptoms, such as dyspnoea, and improve quality of life. Therapeutic patient education as part of respiratory rehabilitation may suffice for minor disorders. 


\section{Cognitive impairment}

A study published in 2006 on 134 patients followed for 32 months evaluated cognitive performance by the ability to copy a simple drawing. The presence of cognitive impairment could be an independent risk factor for mortality (fig. 2) [74].

\section{Osteoporosis}

\section{Definition and epidemiology}

Osteoporosis is characterised by decreased skeletal resistance through deterioration of the microarchitecture of bone tissue, leading to reduced bone mass and lower mineral content. The consequences are bone fragility and increased fracture risk. It is currently defined by a bone mineral density $\geqslant 2.5 \mathrm{SD}$ below the mean for young adults (T-score $\leqslant-2.5$ ), as measured by bone densitometry. Osteoporosis-related fractures preferentially affect the spine, hip and wrist. Osteopenia corresponds to a "preclinical" stage and is defined as a T-score of between -2.5 and -1 . The prevalence of bone disorders increases with the age: it is estimated that $8-18 \%$ of females and $5-6 \%$ of males $>50$ years of age have osteoporosis [75]. As COPD is a disorder of the second half of life, this comorbidity is to be expected. The respiratory complications of osteoporosis are even more marked in COPD because they exacerbate the pre-existing physical inactivity and increase the risk of vertebral fractures, with total lung capacity becoming progressively reduced as the number of vertebral fractures increases. These fractures can also lead to kyphosis, which restricts inhalation movements and reduces lung function parameters (9\% reduction in FVC per fracture, and reduced FEV1).

Epidemiological studies show that the prevalence of osteoporosis in COPD patients is increased. GRAAT-VERBBOM et al. [76] conducted a systematic review of 13 cross-sectional studies published between 1998 and 2008, including a total of 775 COPD patients. The analytical methods and definitions of osteoporosis varied between the studies. According to the World Health Organization definition and based on bone densitometry, the prevalence of osteoporosis ranged from $24 \%$ to $69 \%$. The COPD patients with osteoporosis had significantly lower FEV1 and BMI values than those without osteoporosis. There is a negative correlation between osteoporosis and FEV1 values. Some therapeutic trials include a placebo arm to take into account the natural course; the duration of these trials was nevertheless limited to a few years. SCANLON et al. [77] showed a significant reduction in bone density over 3 years in the triamcinolone-treated group $(-1.66 \pm 4.4)$, but not in the placebo group $(0.1 \pm 4.04) .24 \%$ of the patients in a subgroup of the TORCH study had osteoporosis at the time of trial entry [78]; after 3 years, the changes in bone density were small and similar in all of the groups, as was the incidence of bone fractures. Finally, a study by Mineo et al. [79] evaluated the bone density of 40 patients before and 1 year after lung volume reduction

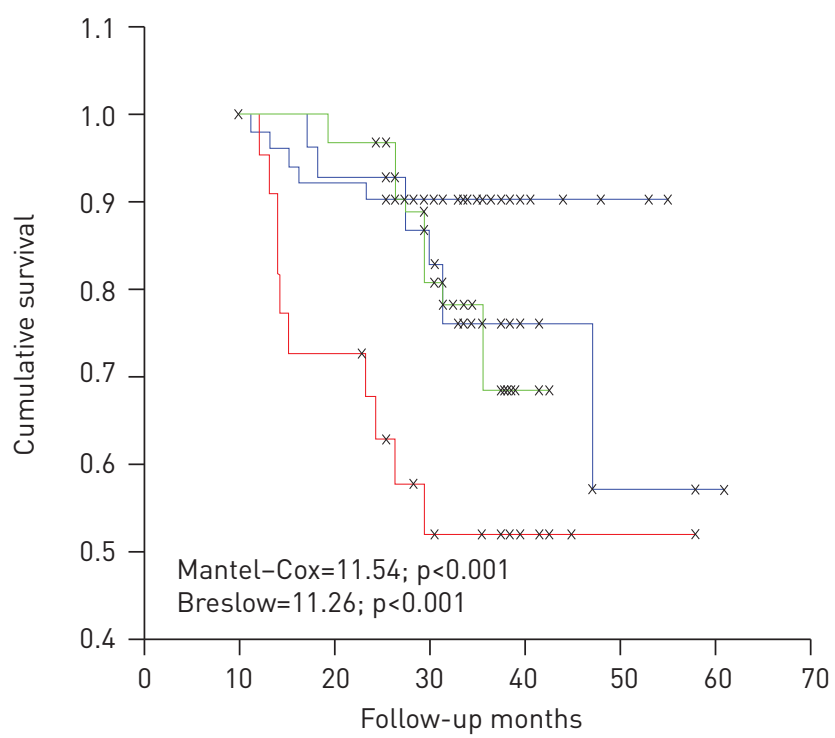

FIGURE 2 Evaluation of cognitive performance based on the ability to copy a simple drawing. Cognitive impairment is a negative predictor of survival in chronic obstructive pulmonary disease patients. Black line: normal copying drawings with landmarks and no hypoxaemia; blue line: normal copying drawings with landmarks and hypoxaemia; green line: impaired copying drawings with landmarks and no hypoxaemia; red line: impaired copying drawings with landmarks and hypoxaemia. Reproduced from [74] with permission from the publisher. 
surgery for emphysema. It suggested that this surgery improved bone density, despite oral steroid therapy, which was maintained after surgery in over half of the patients.

The prevalence of even asymptomatic vertebral fractures in COPD patients is of concern, if only because it accelerates their declining lung function. In the Evaluation of Obstructive Lung Disease and Osteoporosis (EOLO) study, the prevalence of vertebral fractures in an ambulatory COPD population was $41 \%$, and correlated with COPD severity [80].

\section{Pathophysiology}

Pathophysiological evidence supports the epidemiological observations and sheds light on the potential relationships between the two conditions.

At the cellular level, bone remodelling is regulated by three effectors: 1) the osteoblasts that form the bone matrix, which is subsequently calcified; 2) the osteoclasts that resorb bone; and 3) the osteocytes that coordinate bone remodelling. In addition, three regulatory pathways control the interactions between osteoblasts and osteoclasts.

The first involves direct interaction between these two cells via the receptor activator of NF- $\kappa \mathrm{B}$ ligand (RANKL) present at the surface of osteoblasts and its receptor RANK at the surface of pro-osteoclasts, enabling the latter to differentiate into activated osteoclasts. The second pathway involved osteoprotegerin, a protein secreted by stromal cells and osteoblasts. It blocks the interaction between RANK and RANKL, reducing bone resorption. Finally, the $\mathrm{Wnt} / \beta$-catenin regulatory pathway downstream of osteoblast activators remains poorly understood.

\section{Risk factors}

The known shared risk factors for COPD and osteoporosis are interlinked. Smoking and systemic inflammation affect RANK/RANKL binding, and vitamin D deficiency stimulates parathormone secretion and affects osteoclast maturation through its effect on RANK/RANKL. Recent data show that inflammatory cytokines can also target Wnt. Vitamin D can also improve the expression of the osteoprotegerin/RANKL complex, reducing osteoclast formation. Oral steroid therapy affects bone homeostasis through increased expression of RANKL, decreased osteoprotegerin and suppression of osteoclast apoptosis. The hypogonadism present in COPD also plays a part in the development of osteoporosis: the drop in oestrogen levels inhibits the action of the osteoprotegerin/RANKL complex.

Although an association between smoking and osteoporosis has been established, the studies do not report lung function values [81]. The lower levels of physical activity commonly found in COPD patients have a negative effect on bone metabolism, a phenomenon that has been clearly demonstrated in post-menopausal females. A negative impact of vitamin D deficiency on bone homeostasis has been suggested: its frequency increases with COPD stage, reaching 77\% for the very severe stage according to JANSSENS et al. [82]. More generally, malnutrition has a negative impact and is another common finding in COPD. The importance of the harmful effect of systemic inflammation, related to COPD severity, has been highlighted previously [83]: pro-inflammatory cytokines, such as IL-1 $\beta$, IL- 6 and TNF- $\alpha$, may promote bone resorption. The harmful effect of oral steroid therapy on bone metabolism has long been established, and recent studies of the underlying mechanism have highlighted the impact of oral steroid therapy on both bone resorption and impaired bone formation.

\section{Treatment and prevention}

The treatment and prevention of osteoporosis in COPD patients requires non-pharmacological measures. Besides smoking cessation, which is crucial, the chief measure is respiratory rehabilitation: it has been shown in exercise retraining programmes to improve bone mineral density. Such data are lacking in COPD patients, although the indirect effects of such programmes improve muscle strength and balance, and reduce the risk of falling.

Calcium and vitamin D supplementation have proven effective in reducing fracture risk, the effect being dose-dependent for vitamin D and only when combined with calcium [84]. Several recent studies on vitamin $\mathrm{D}$ have found it to improve muscle function and postural stability, and to have immunomodulatory effects. A daily dose of $800 \mathrm{IU}$ of vitamin D combined with calcium supplementation is recommended for patients with a T-score of $<-1$ and three minor risk factors (BMI $<21 \mathrm{~kg} \cdot \mathrm{m}^{-2}$, active smoking, chronic alcohol abuse, age $>65$ years, hip fracture, rib fracture, menopause, sedentary lifestyle and FEV $1<50 \%$ predicted) or one major risk factor (systemic corticosteroid therapy for $>3$ months per year, previous vertebral compression fracture). Bisphosphonate therapy has not been specifically evaluated for osteoporosis in COPD patients, although research by SMITH et al. [85] suggests it has a beneficial effect on the T-scores of patients with airways disease. The usefulness in COPD of new treatments such as 
teriparatide remains to be defined, whereas its role in the treatment of glucocorticoid-induced osteoporosis is now well established [86].

\section{Malnutrition}

\section{Definition}

In COPD, patients are usually said to be malnourished when their BMI is $<20 \mathrm{~kg} \cdot \mathrm{m}^{-2}$. Malnutrition reduces the lean body mass (muscle). Lean body mass can be evaluated by dual-energy absorptiometry (expensive equipment), by measuring skin fold thickness (often inappropriate in elderly subjects) or by bioelectrical impedance analysis. The latter method tends to be preferred in routine practice.

Three malnutrition profiles can be identified in COPD: underweight patients with concomitant depletion of lean body mass $(60 \%)$, underweight patients with a normal lean body mass $(20 \%)$ and patients of stable body weight with depletion of lean body mass [87].

The importance of considering nutritional status is underlined by the prognostic power of the BODE (BMI, airflow obstruction, dyspnoea and exercise capacity) index [88], which takes into account FEV1, 6-min walking distance, dyspnoea and BMI.

\section{Pathophysiology}

Malnutrition in COPD is the consequence of an imbalance between energy intake and consumption. Inadequate intake is caused by dyspnoea resulting from the effort of eating and by impaired leptin regulation, a hormone that reduces food intake [89]. The reasons for increased energy consumption are unclear but include work of breathing, smoking and medication, including theophylline and $\beta$-blockers. Other factors, such as increased protein catabolism due to systemic inflammation, hypoandrogenism and hypoxia, also seem to be involved.

\section{Prevalence}

The prevalence depends on COPD stage and the definition of nutritional status used. At the chronic respiratory failure stage, $17 \%$ of patients have a BMI $<20 \mathrm{~kg} \cdot \mathrm{m}^{-2}$ [90]. In the Danish cohort [91], 0-5\% of patients with GOLD grade 0-2 COPD had a BMI $<18.5 \mathrm{~kg} \cdot \mathrm{m}^{-2}$ versus $15-30 \%$ of patients with grade 4 disease. In this study, malnutrition was more marked in females than males, irrespective of COPD stage.

\section{Morbidity and mortality}

Several European cohort studies (table 1) have shown a link between malnutrition and mortality [91-95]. In the Danish cohort, for patients with an FEV $1<50 \%$ pred the relative risk for death was a HR of 1.62 (95\% CI 1.15-2.31) for a BMI $<20 \mathrm{~kg} \cdot \mathrm{m}^{-2}$ and $0.62(95 \%$ CI $0.41-0.94)$ for patients with a BMI $\geqslant 30 \mathrm{~kg} \cdot \mathrm{m}^{-2}$.

\section{Nutritional rehabilitation}

After diagnosing malnutrition, the treatment options available to clinicians are: physical exercise as part of respiratory rehabilitation; caloric, protein and polyunsaturated fatty acid supplementation [96-99]; and anabolic steroids $[100,101]$.

These approaches can be integrated in a standardised programme. The term nutritional rehabilitation was proposed by SCHOLS [102] and taken up by others [103].

\section{Obesity}

There are few factual data on the link between obesity and COPD. However, an obesity (or at least overweight) paradox appears to exist. Obesity does not worsen the respiratory function symptoms of COPD [104] and it even has a protective effect in relation to mortality [91, 105], although the picture differs in morbid obesity $\left(\mathrm{BMI}>40 \mathrm{~kg} \cdot \mathrm{m}^{-2}\right)$. JORDAN et al. [106] reported a significant increase in deaths due to respiratory disease in subjects with a BMI $>40 \mathrm{~kg} \cdot \mathrm{m}^{-2}$ (HR 5.78, 95\% CI 1.09-30.61). Obese patients, especially those with COPD, should be investigated for obstructive sleep apnoea syndrome (OSAS) and obesity hypoventilation syndrome.

\section{Metabolic syndrome and diabetes}

Metabolic complications are common comorbidities of COPD, namely type 2 diabetes and metabolic syndrome.

\section{Definitions}

Diabetes mellitus is defined by insufficient secretion or effect of insulin. The clinical and laboratory signs of diabetes are polyuria-polydipsia syndrome, blood glucose $>11.1 \mathrm{mmol} \cdot \mathrm{L}^{-1}$ or a fasting blood glucose 
TABLE 1 Studies reporting a link between body mass index (BMI) or body composition and mortality

$\begin{array}{lllll}\text { First author } & \text { Study } & \text { Subjects } \mathrm{n} & \text { Follow-up } & \text { Severity }\end{array}$

[ref.]

\begin{tabular}{|c|c|c|c|c|}
\hline SchoLs [92] & $\begin{array}{l}\text { Single-centre } \\
\text { retrospective cohort }\end{array}$ & 412 & 48 months & Mean FEV1 39\% \\
\hline LANDBO [93] & $\begin{array}{c}\text { CCHS prospective } \\
\text { cohort }\end{array}$ & 2132 & 17 years & Mean FEV 16 \\
\hline
\end{tabular}

Chailleux [94]

Soler-CATAluna

[95]

Vestbo [91]

\author{
CCHS prospective \\ cohort
}

$\begin{array}{cc}4088 & \begin{array}{c}7.5 \text { years } \\ \text { (average) }\end{array} \\ 96 & 3 \text { years }\end{array}$

FEV1 $630-860 \mathrm{~mL}$ LTOT etrospective cohor prospective cohort const
1898

7 years

GOLD 0-IV
FFMI predicts mortality independently of BMI, fat mass, age and sex Low BMI $\left(<20 \mathrm{~kg} \cdot \mathrm{m}^{-2}\right)$ versus normal BMI (20-25)

Male: RR 1.64 (95\% Cl 1.2-2.23) Female: RR 1.42

Low BMI is a risk factor for mortality, independently of age, FEV1, $\mathrm{PaO}_{2}$ and sex Anthropometric measurement of muscle depletion $\leqslant 25$ th percentile associated with higher mortality after 12 months $(12 \%$ versus $5.9 \%), 24$ months ( $31 \%$ versus $7.9 \%$ ) and 36 months $(39.2 \%$ versus $13 \%)$

Percentage of malnourished subjects is higher in females than males Low BMI increases risk of overall mortality (HR 1.8) and COPD-related mortality (HR 3.2)

CCHS: Copenhagen City Heart Study; ANTADIR: Observatory of Association Nationale pour le Traitement a Domicile de l'Insuffisance Respiratoire Chronique; FEV1: forced expiratory volume in $1 \mathrm{~s}$; LTOT: long-term oxygen therapy; GOLD: Global Initiative for Chronic Obstructive Lung Disease; FFMI: fat-free mass index; RR: relative risk; $\mathrm{PaO}_{2}$ : arterial oxygen tension; HR: hazard ratio; COPD: chronic obstructive pulmonary disease.

$>7 \mathrm{mmol} \cdot \mathrm{L}^{-1}$, a 2 -h post-prandial blood glucose $>11.1 \mathrm{mmol} \cdot \mathrm{L}^{-1}$ with $\mathrm{HbAlc} \geqslant 6.5 \%$. The definitions of metabolic syndrome are summarised in table 2 [109].

\section{Epidemiology}

The prevalence of diabetes in COPD patients varies between studies: $10.3 \%$ in a population of grade $2 / 3$ COPD patients in a rehabilitation centre according to CRISAFUlLI et al. [4], 12.6-14.5\% in an all-stage COPD population according to MANNINO et al. [110], 12.2\% with an increased risk in active smokers according to FEARY et al. [111] and $18.7 \%$ according to CAZZOLA et al. [112]. The prevalence of metabolic syndrome is $22.5 \%$ for all grades according to GHANASSIA et al. [113], and 53\% for GOLD grade 2 COPD, $37 \%$ for GOLD grade 3 COPD and 44\% for GOLD grade 4 COPD according to WATZ et al. [114]. In the latter study, the presence of metabolic syndrome was associated with higher levels of the markers of systemic inflammation, CRP and IL-6.

TABLE 2 Definitions of metabolic syndrome according to the World Health Organization (WHO) and the International Diabetes Federation (IDF)

\section{Criterion}

Blood glucose
Plasma triglycerides
HDL cholesterol

Abdominal (central) obesity

\section{Blood pressure}

Urinary albumin excretion rate
WHO definition [107] ${ }^{\#}$

IDF definition [108] $\geqslant 1 \mathrm{~g} \cdot \mathrm{L}^{-1}$ or specific treatment

$$
\geqslant 1.5 \mathrm{~g} \cdot \mathrm{L}^{-1}
$$

$<0.4 \mathrm{~g} \cdot \mathrm{L}^{-1}$ for males and $<0.5 \mathrm{~g} \cdot \mathrm{L}^{-1}$ for females

or specific treatment

Waist circumference $\geqslant 94 \mathrm{~cm}$ for males and $\geqslant 80 \mathrm{~cm}$ for females for Europids

$\mathrm{SBP}>130 \mathrm{mmHg}$ or $\mathrm{DBP}>85 \mathrm{mmHg}$ or antihypertensive treatment

HDL: high-density lipoprotein; BMI: body mass index; SBP: systolic blood pressure; DBP: diastolic blood pressure. ${ }^{\text {: }}$ diabetes with two other criteria; ": abdominal obesity with two other criteria. 
Cohort studies have shown that moderate to severe COPD increases the risk of diabetes (OR 1.4 and 1.5, respectively) [110]. In a large cohort of females, SONG et al. [115] showed that the presence of asthma or COPD was associated with a risk of developing type 2 diabetes, suggesting that airway inflammation contributes to the pathophysiology of diabetes. Conversely, in a US cohort, the relative risk of developing COPD was higher (HR 1.22) in patients with diabetes than in non-diabetics [116].

\section{Mortality}

Diabetes also affects the prognosis of COPD (time to first hospitalisation and 5-year mortality rate) [110]. According to the Emerging Risk Factors Collaboration [117], the HR for COPD-related death was 1.27 compared to subjects without diabetes. BAKER et al. [118] showed that an increase in blood glucose of $1 \mathrm{mmol} \cdot \mathrm{L}^{-1}$ increases the risk of death by $15 \%$. PARRAPIL et al. [119] confirmed an increased risk of death (OR 1.93) and hospital stays were $10.3 \%$ longer for patients with diabetes hospitalised for COPD exacerbation.

\section{Pathophysiology}

Systemic inflammation (with elevated markers such as CRP, TNF- $\alpha$ and IL-6) plays an important role in both the progression of COPD and the development of insulin resistance. Smoking is one cause of inflammation, which may explain the data reported by FEARY et al. [111] and MANSON et al. [120]: smokers have a two-fold higher risk of developing diabetes than nonsmokers.

A recent review of the literature demonstrated the complex link between smoking and obesity in the development of comorbidities, involving an enzyme cascade that originates in adipose tissue considered a site for production of cytokines (TNF- $\alpha$, IL-6, etc.) while adiponectin decreases with increased adiposity. This increases insulin resistance, circulating free radicals and oxidative stress, exacerbating the initial pulmonary inflammation. Adipose tissue stimulation is promoted by tissue hypoxia, smoking and the degree of bronchial obstruction [121-124]. The elevation of inflammatory markers (IL-6, TNF- $\alpha$, CRP, etc.) correlates strongly with weight gain. Metabolic syndrome is also associated with a pro-inflammatory and prothrombotic state [123].

\section{Mechanisms}

The pulmonary consequences of diabetes and metabolic syndrome lead to a somewhat restrictive pattern, with significantly lower FEV1 and FVC values than in non-diabetics, even after adjustment for age, sex, BMI, smoking status, diabetes duration and HbAlc levels [125-128]. Two Asian cohort studies, including $>7000$ patients, investigated metabolic syndrome, showing a link between airway obstruction and central obesity [129, 130]. LEONE et al. [128] also found a strong correlation between metabolic syndrome and impaired lung function, which was especially stronger in active smokers or former smokers. Abdominal obesity had a dominant role, and subcutaneous and intra-abdominal adipose tissue correlated with circulating levels of IL- 6 and TNF- $\alpha$, while there was a negative correlation with levels of adiponectin, which plays a role in insulin sensitivity. The mechanisms underlying lung volume restriction could include a combination of abdominal obesity, reduced pulmonary elasticity through non-enzymatic glycosylation of tissue proteins, loss of inspiratory muscle strength and/or diaphragmatic compromise due to diabetic neuropathy. Post mortem series also show diffuse thickening of the alveolar membranes and centrilobular emphysema [131].

\section{Impact of treatments}

What is the role of the various treatments used in COPD in insulin resistance? The role of $\beta_{2}$-agonists and oral steroid therapy has already been demonstrated [132]. SuISSA et al. [133] confirmed that high-dose inhaled corticosteroids are a risk factor for the development or poor control of diabetes.

When can metformin be used in COPD? The contraindications to metformin are typically renal failure, congestive heart failure, acute or chronic metabolic acidosis, hepatic insufficiency and conditions that may cause tissue hypoxia, such as respiratory failure. Age $>80$ years, alcohol abuse and concomitant treatment with nephrotoxic drugs are relative contraindications. They are associated with the risk of lactic acidosis [134]. Metformin should also be discontinued in situations where there is a risk of acute renal failure, such as intravascular contrast media (discontinued for 3 days) in radiological studies, sepsis, hepatitis or gastrointestinal disturbances involving diarrhoea and vomiting, or of acute hypoxia, such as during acute cardiac or respiratory failure or perioperatively $[135,136]$. However, there is some debate in the literature over the causality of metformin and the contraindications. Several authors have also demonstrated that it is regularly administered to patients who have two or three risk factors [137, 138]. RACHMANI et al. [139], whose study included $\sim 40$ grade 3 COPD patients in each group, came to the same conclusion, with no harmful consequences. There have been some reports of episodes of lactic acidosis, in which COPD was cited in the history or as a risk factor, but none reported the severity of the COPD [140,141] and the causes of the acute episode are dominated by acute renal failure, cardiogenic or septic shock and hepatic insufficiency. SCALE and 
HARVEY [142] reviewed the 48 cases of lactic acidosis that occurred in patients with type 2 diabetes (out of a total of 149) and looked for predisposing factors: COPD was not mentioned. It appears, therefore, that unless respiratory failure is present, COPD is not a contraindication to metformin therapy.

As regards using statins to treat the dyslipidaemia associated with metabolic syndrome, they may have an anti-inflammatory, antioxidant and immunomodulatory effect [143]. They may also have an effect on pulmonary hypertension in COPD [144, 145]. Treatments for hypertension or heart failure in patients with diabetes (angiotensin-converting enzyme inhibitors, angiotensin II blockers and cardioselective $\beta$-blockers) may reduce COPD exacerbations and mortality through an anti-inflammatory effect and by delaying the onset of pulmonary arterial hypertension [144-146].

\section{Sleep disturbance \\ Epidemiology}

Impaired sleep quality is common in COPD. It was first demonstrated in questionnaire-based studies, with or without sleep studies. According to CORMICK et al. [147], out of a population of 50 patients with severe COPD, $36 \%$ complained of trouble falling asleep, $42 \%$ of non-restorative sleep and $76 \%$ of more than two prolonged periods of wakefulness per night, while $28 \%$ were using hypnotics. Sleep studies confirmed that the total sleep period, total sleep time and non-rapid eye movement (REM) sleep time were reduced, while sleep latency, arousals and the number sleep state changes were increased. According to KLINK et al. [148], $35.9 \%$ of patients in the TESOAD (Tucson Epidemiologic Study of Chronic Lung Disease) cohort with airway obstruction had sleep disturbances, based on questionnaire data. The risk factors were respiratory symptoms, female sex, increasing age and obesity. DoDGe et al. [149] showed that for $60 \%$ of patients, sleep disturbances persisted between two evaluations separated by an interval of 7 years conducted in the same population, with the incidence of sleep disturbances being increased by the presence of respiratory symptoms and in age groups over 45 years of age.

Impaired sleep quality appears to be more common in patients with severe COPD. The analysis of the Sleep Heart Health Study [150], which focused on patients with moderate COPD, did not find sleep quality or architecture to be significantly impaired in the absence of OSAS, whereas KRACHMAN and co-workers [151, 152] confirmed the data of CORMICK et al. [147] in severe COPD. More recently, VALIPOUR et al. [153] found that sleep quality was impaired, based on both questionnaire data (the Sleep Disorders Questionnaire: difficulty initiating or maintaining sleep $(\mathrm{p}<0.001)$, and sleep problems resembling anxiety and depressive disorder $(\mathrm{p}<0.035)$ ) and polysomnographic evaluation (reduced total sleep time: 4.7 versus $5.5 \mathrm{~h}(\mathrm{p}<0.05)$; sleep efficacy: $75 \%$ versus $82 \%(\mathrm{p}<0.01)$; percentage of REM sleep: $14 \%$ versus $17 \%(\mathrm{p}<0.05))$ in 52 patients with moderate COPD compared to 52 controls. According to BUDHIRAJA et al. [154], COPD is a risk factor for insomnia, with an odds ratio of $1.9(95 \%$ CI $1.5-2.5 ; \mathrm{p}<0.001)$ relative to a control population.

However, excessive daytime sleepiness is not as widespread: $19.5 \%$ among patients with obstructive airway disease according to KLINK et al. [148], which was not significantly different from patients without airway obstruction, but was more frequent in subjects who regularly snore; while VALIPOUR et al. [153] found that the sleepiness scores of COPD patients and controls did not differ significantly.

\section{Mechanisms}

There are multiple causes for poor-quality sleep. One hypothesis is distension and increased work of breathing, potentiated when lying down $[152,155]$, which is supported by the improvement in sleep in patients who have undergone lung volume reduction surgery [156]. Respiratory symptoms (dyspnoea, cough and expectoration) can cause arousal. There is no consensus over the role of nocturnal hypoxia, but there appears to be no correlation between sleep quality (total sleep time and sleep efficacy) and nocturnal arterial oxygen saturation [152, 156, 157].

According to Lo COCO et al. [158], based on interview data, one-third of COPD patients have restless legs syndrome and $62 \%$ of these patients complain of sleep disturbances: periodic limb movement syndrome can contribute to this phenomenon. Anxiety and reactive depression are common in COPD patients and cause sleep disturbances.

Pain can disturb sleep initiation or wake patients during the night: $25.7 \%$ of patients reported pain in the Pittsburgh questionnaire in the study by SCHARF et al. [159]. Finally, the presence of OSAS exacerbates sleep disturbances in COPD patients [150].

\section{Impact of treatments}

Exclusively nocturnal oxygen therapy has not been validated in prospective studies [160, 161]. Long-acting inhaled bronchodilators do not affect sleep quality $[162,163]$. Studies on indacaterol suggest that it reduces nocturnal awakenings due to dyspnoea, compared to placebo and comparators (tiotropium and salmeterol) 
[164, 165]. Meta-analysis from WIJKSTRA et al. [166] concludes that long-term noninvasive ventilation (NIV) does not improve sleep quality in stable severe COPD. Nevertheless, CuINI et al. [167] and McEvoy et al. [168] found that NIV combined with oxygen therapy slightly improves the sleep of patients with severe hypercapnic COPD compared to oxygen therapy alone. According to CRISAFUlu et al. [169], average volume assured pressure support is as effective and comfortable as fixed ventilation and improves sleep quality.

The main consequences of poor sleep quality are reduced quality of life [170, 171], exacerbation of anxiety and depression, and uncontrolled use of hypnotics, which can be harmful.

The treatment of insomnia in COPD patients involves restricting the time spent in bed, stimulus control, relaxation and cognitive behavioural therapy [172]. Short-term hypnotics can be considered, but not in patients with untreated concomitant OSAS or chronic hypercapnic respiratory failure, or during exacerbations $[173,174]$.

\section{OSAS and COPD}

It is important to consider the possibility of the coexistence of OSAS and COPD, bearing in mind the consequences. OSAS is no more prevalent in COPD than in the general population. According to SANDERS et al. [151], in the $>40$-year-old population of the Sleep Heart Health Study cohort, 22.3\% of patients with obstructive airways disease had an apnoea/hypopnoea index (AHI) $>10$ versus $28.9 \%$ of others $(\mathrm{p}<0.0001)$ and $14 \%$ versus $18.6 \%$ had an AHI $>15(\mathrm{p}<0.0002)$. According to BEDNAREK et al. [175], in the MONICA II (Multinational Monitoring of Trends and Determinants in Cardiovascular Disease) study, the prevalence of OSAS in a COPD population and COPD-free population did not differ significantly: $11.1 \%$ versus $17 \%$, respectively, had an AHI $>10$ (not significant) and $8.3 \%$ versus $12.2 \%$, respectively, had an $\mathrm{AHI}>15$.

The risk factors for OSAS in COPD patients are the same as in the general population. OSAS should be suspected in the presence of typical nocturnal clinical signs (snoring, breathing pauses noticed by the partner, poor sleep, etc.) and daytime signs (non-restorative sleep, headache on awakening, excessive daytime sleepiness), as well as impaired gas exchange or pulmonary hypertension inadequately explained by lung function and blood gas test results. The diagnosis can be confirmed using a type 3 portable monitoring device, with polysomnography rarely being necessary. The OSAS-COPD combination has important consequences: reduced sleep quality, increased nocturnal hypoxaemia and nocturnal desaturation [176, 177], more frequent daytime hypercapnia [176], pulmonary arterial hypertension and more frequent right heart failure than in COPD patients without OSAS or in OSAS patients without COPD [176, 177], higher risk of being admitted into hospital for an exacerbation [178], and higher risk of systemic inflammation and oxidative stress, with additive or synergistic effects playing a role in cardiovascular comorbidities [179]. Finally, the risk of death is increased $[178,180]$. Continuous positive airway pressure (CPAP) is the standard treatment for OSAS. It is effective and improves prognosis (fig. 3) [178, 180].

Oxygen therapy is sometimes given in addition to CPAP when nocturnal hypoxaemia persists (mean $<90 \%$ ) or when the usual criteria for instituting long-term oxygen therapy ( $>16-18 \mathrm{~h}$ per $24 \mathrm{~h}$ ) are met [181]. NIV may be used immediately, depending on the severity of daytime or nocturnal hypoventilation, possibly switching later to CPAP or at a later date if nocturnal hypoventilation (during REM sleep) persists during CPAP therapy. Studies are required to optimise the therapeutic strategy.

\section{Anaemia}

Epidemiology

Anaemia is defined by a haemoglobin concentration of $<13 \mathrm{~g} \cdot \mathrm{dL}^{-1}$ for males and $12 \mathrm{~g} \cdot \mathrm{dL}^{-1}$ for females [182]. Anaemia was recently identified as a comorbidity of COPD. Hypoxaemic smokers would actually be expected to exhibit polycythaemia, but studies that have reported haematological values show that anaemia is more common than polycythaemia, with a prevalence ranging from $12.3 \%$ to $23 \%$ for anaemia and of $6 \%$ for polycythaemia [183-185].

\section{Anaemia and systemic inflammation}

COPD is a systemic inflammatory disease in which IL-1, IL-6 and TNF- $\alpha$ play a role. Many other chronic diseases with systemic inflammation are associated with anaemia, such as cancers and connective tissue diseases. Elevation of IL-1, IL-6 and TNF- $\alpha$, which have a harmful effect on erythropoiesis, is also found in these diseases [186]. However, although several authors have demonstrated an association between the presence of anaemia and markers of inflammation such as CRP in COPD patients [187, 188], there is currently no evidence of a direct role for COPD-related inflammation in the anaemia observed. 

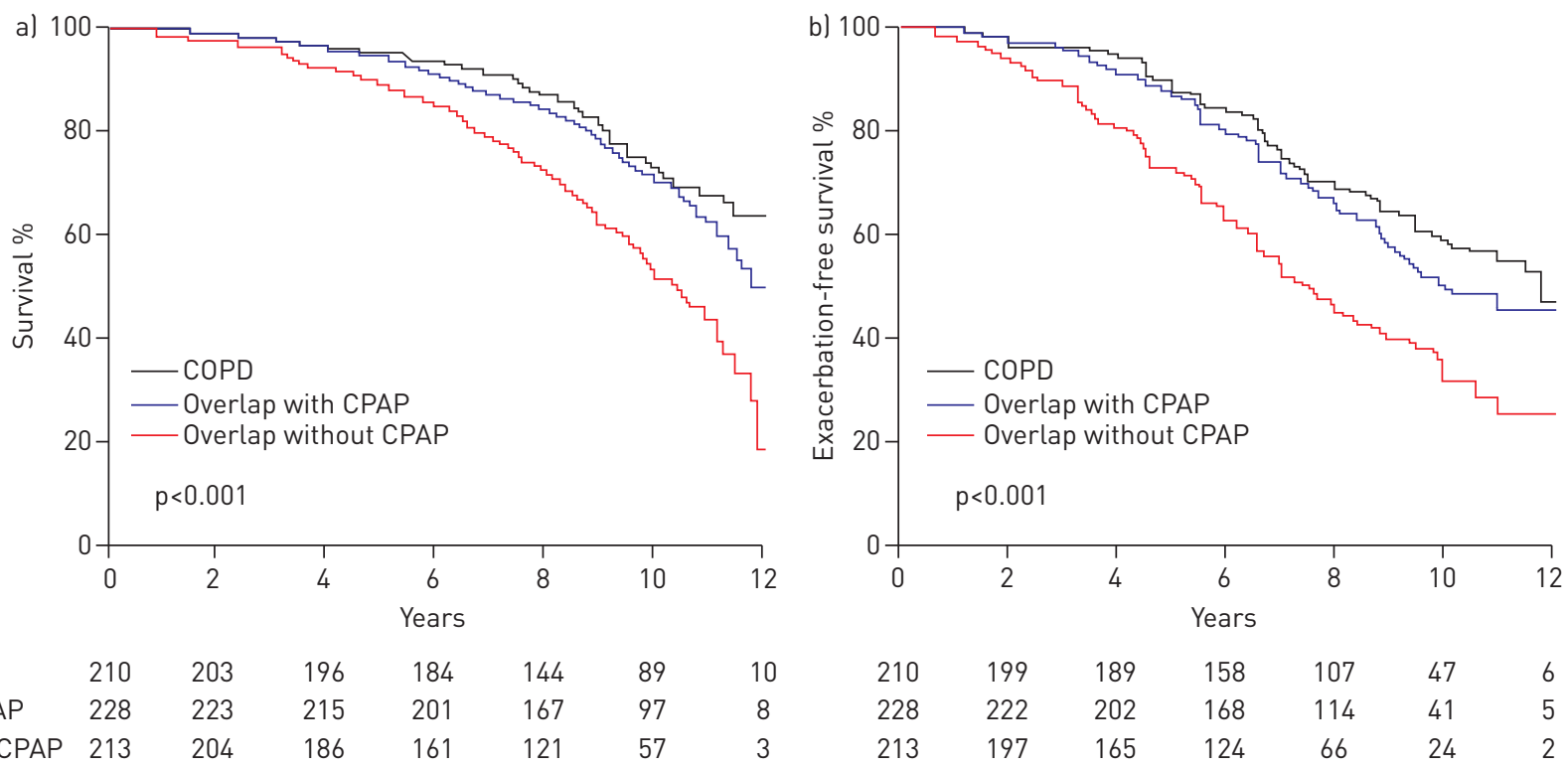

FIGURE 3 Comparison of a) survival and b) exacerbation-free survival in three populations: chronic obstructive pulmonary disease (COPD) alone; COPD with obstructive sleep apnoea syndrome (OSAS) treated with continuous positive airway pressure (CPAP); and COPD with OSAS not treated with CPAP. Reproduced from [178] with permission from the publisher.

\section{Confounding factors}

There are many confounding factors associated with COPD, such as old age, malnutrition and cardiovascular disease, which can also be responsible for anaemia. Malnutrition can be associated with iron, folate or vitamin B12 deficiency, all of which can result in anaemia. Anaemia is also a frequent comorbidity in heart failure patients, with a prevalence of 15\% [189-192]. It is due to the chronic inflammation associated with heart disease, as well as activation of the renin angiotensin system that causes some degree of haemodilution [192].

There are, therefore, many confounding factors that are very important in the development of anaemia. It is advisable to screen for them in anaemic COPD patients.

\section{The impact of anaemia in COPD}

Few studies have looked at the consequences of anaemia on patients with COPD. KRISHNAN et al. [193] showed that anaemia is associated with reduced quality of life in COPD patients.

COTE et al. [183] studied 683 COPD patients, 116 of whom had a haemoglobin concentration $<13 \mathrm{~g} \cdot \mathrm{dL}^{-1}$. They demonstrated several significant differences in the anaemic patients, independently of age, FEV1, other comorbidities and BMI. Their dyspnoea score was generally higher. Their exercise capacity was lower, indicated by a shorter 6-min walking distance. Finally, the survival rate of anaemic COPD patients was significantly lower.

The same is true for patients with chronic obstructive respiratory failure. CHAMBELLAN et al. [184] studied a cohort of 2524 oxygen-dependent COPD patients. They showed that anaemia was an independent negative predictor of the rate and cumulative duration of hospitalisation and of the survival of COPD patients receiving oxygen therapy.

Anaemia therefore has a negative impact on the prognosis of COPD patients. It also interferes with their treatment, because respiratory rehabilitation is compromised by the patients' reduced exercise capacity. The treatment of anaemia therefore seems to be a possible target for improving the clinical management of COPD.

\section{Treating anaemia in COPD}

There are very few studies on this subject. SCHONHOFER et al. [194] showed that blood transfusion significantly reduced the work of breathing and improved withdrawal of ventilation in a group of 11 anaemic COPD patients in critical care. The use of erythropoietin (EPO) would be easier to implement in practice. EPO therapy has been studied extensively in heart failure. A recent meta-analysis showed that EPO improves survival in anaemic patients and patients with heart failure [195]. EPO appears to be a promising approach for treating anaemia in chronic diseases, but no studies have yet been conducted in COPD. 


\section{Lung fibrosis}

Smoking is a common risk factor for lung fibrosis and COPD. In a cohort of 2416 smokers, interstitial lung lesion was found in $8 \%$ of case by high-resolution computed tomography [196]. So, the proportion of interstitial lung disease in the smoker population is not negligible and it can be associated with COPD, which is a frequent disease in the same population. Indeed, combined pulmonary fibrosis and emphysema (CPFE) is a clinical syndrome which is now well described.

\section{Pulmonary function tests}

Patients with this entity have specific pulmonary function tests. There are characterised by relatively normal spirometry and lung volumes in the setting of severely impaired gas exchange. The normal lung volumes are explained by the inverse effect of the restriction seen in pulmonary fibrosis and the hyperinflation seen in emphysema. The normal spirometry is secondary to the association of bronchus obstruction and collapse in emphysema and inversely airway traction by peribronchial fibrosis. At the same time, reduction of vascular surface in emphysema and the alveolar membrane thickening due to fibrosis combine to reduce gas exchange. This exchange gas reduction explains that CPFE syndrome is characterised by a patient with severe breathless and hypoxaemia.

\section{Computed tomography scan}

The CPFE syndrome computed tomography scan is characterised by an upper lobe emphysema and lower lobe pulmonary fibrosis. Bullous, paraseptal and centrolobular emphysema are the most frequent upper lobe abnormalities. In the lower lobe, honeycombing, reticular intralobular opacities and traction bronchiectasis are the most frequent findings. Idiopathic pulmonary fibrosis (IPF) and nonspecific interstitial pneumonia are the main reported pathological patterns of pulmonary fibrosis [197].

\section{Complications and mortality}

Patients with CPFE syndrome have different complications and mortality than those with pulmonary fibrosis or emphysema alone.

$\mathrm{PH}$ is the most important morbidity of CPFE. It seems to be more frequent and more severe in CPFE patients than in patients with IPF alone. In a cohort of 40 patients with right heart catheterisation, CoTTIN [198] found that a reduced cardiac index or an elevated PVR were predictors of poor prognosis.

Lung cancer is also associated with CPFE. The prevalence appears to be higher in the CPFE population than in the general population or in COPD patients alone [199].

In terms of mortality, patients with CPFE syndrome have a significantly reduced survival compared to COPD patients alone. Median survival in a cohort of patients is $\sim 6$ years [194]. Except for lung transplantation, there is no specific treatment that improves patients' median survival.

\section{Comorbidities and COPD exacerbation}

In the ECLIPSE (Evaluation of COPD Longitudinally to Identify Predictive Surrogate End-points) cohort, the authors studied 2164 clinically stable COPD patients. They showed that a severe bronchial obstruction was not sufficient to explain COPD exacerbations [200].

To better characterise the COPD patients phenotypes, Burgel et al. [201] used cluster analyses. They defined two COPD patient groups who had frequent exacerbations. The first group had a severe obstructive syndrome. The second group had a moderate obstructive syndrome but also comorbidities. Thus this study suggested that there is a real relationship between comorbidities and exacerbations.

\section{COPD exacerbations impact on comorbidities}

We showed in this review that systemic inflammation in COPD is very important in the physiopathology of all comorbidities. Some studies showed that this inflammation increases during COPD exacerbations with an elevation of oxidative stress, plasma fibrinogen and serum IL-6 levels [202, 203], suggesting that COPD exacerbations can increase comorbidities.

Indeed, some studies suggest that coronary heart disease can be increased by exacerbations. After analysing data from 25857 patients with COPD over a 2-year period, DONALDSON et al. [204] found that the risk of myocardial infarction is increased 2.27-fold during the 5 days following the onset of an exacerbation, defined by the use of steroids or antibiotics.

However, exacerbations can have an impact on osteoporosis and malnutrition of COPD patients. KIYOKAWA et al. [205] followed up 42 patients for whom exacerbations were recorded and thoracic vertebral 
bone mineral density was measured using chest computed tomography. In this way, they demonstrated that COPD exacerbations are independently associated with osteoporosis progression.

Acute exacerbation of COPD is accompanied by an impaired energy balance due to decreased dietary intake and increased resting energy expenditure. It has a negative consequence on patient's nutritional status after repeated exacerbations [206].

\section{COPD comorbidities impact on exacerbations}

The role of venous thromboembolism in causing COPD exacerbation is not well known and it must to be sought to end doubt. Other comorbidities have an impact on exacerbation appearance. In a retrospective post mortem analysis of patients who died early during COPD exacerbations, the authors showed that heart failure and lung embolism were the principal causes of death [207].

Other comorbidities linked in less obvious ways to COPD exacerbation have also been studied. Indeed, anxiety was found to be related to increased risk of relapse after exacerbation [208] and hospital readmission [209]. The role of depression on exacerbation is less clear but it has prognostic value because it extends the duration of hospitalisation $[69,210]$. In the same way, metabolic syndrome has an impact in exacerbation. According to KüPELI et al. [211], patients with metabolic syndrome had more exacerbations over an 18 -month period $(2.4$ versus $0.68, \mathrm{p}<0.001)$. During a COPD exacerbation, hyperglycaemia is associated with a higher risk of prolonged hospitalisation or death than normal blood glucose levels.

\section{Conclusion}

In this review we showed that COPD is frequently associated with other diseases. There is consistent evidence that these comorbidities have a greater negative impact in COPD patients in terms of quality of life, exacerbation and mortality. Thus, diagnosis and management of comorbidities is an important challenge for the COPD patient. Consequently, the COPD guidelines take into account these comorbidities. Indeed, the revised GOLD document has included a chapter giving simple advice to the clinician managing patients with COPD and comorbidities. In these guidelines, diseases associated with COPD should be assessed and treated according to usual guidelines, as there is no evidence that comorbidities should be treated differently in the presence of COPD (GOLD). But it is not always easy to diagnose the coexisting illness. Indeed, these can be asymptomatic or the symptoms may not be specific in COPD patient. Thus, systematic research of comorbidities seems to be of interest. BMI, the HAD scale, ECG and chest radiography are easy to obtain in medical practice and should be regularly used to assess COPD patients. Transthoracic echocardiography, bone mineral density assessment and computed tomography should be also performed for clinically significant COPD or when other risk factors are associated.

\section{Acknowledgements}

We were assisted in the preparation of this article by HealthExperts SA and Matrix Consultants (both Paris, France).

\section{References}

1 Global Initiative for Chronic Obstructive Lung Disease (GOLD). Global strategy for the diagnosis, management and prevention of chronic obstructive pulmonary disease. www.goldcopd.org Date last updated: February 2013. Date last accessed: February 15, 2013.

2 Haute Autorité de Santé (France). Prescrire chez le sujet âgé. www.has-sante.fr Date last updated: January 2006. Date last accessed: February 15, 2013.

3 van Durme YM, Verhamme KM, Stijnen T, et al. Prevalence, incidence, and lifetime risk for the development of COPD in the elderly: the Rotterdam study. Chest 2009; 135: 368-377.

4 Crisafulli E, Costi S, Luppi F, et al. Role of comorbidities in a cohort of patients with COPD undergoing pulmonary rehabilitation. Thorax 2008; 63: 487-492.

5 Celli BR, Thomas NE, Anderson JA, et al. Effect of pharmacotherapy on rate of decline of lung function in chronic obstructive pulmonary disease: results from the TORCH study. Am J Respir Crit Care Med 2008; 178: 332-338.

6 Tashkin DP, Celli B, Senn S, et al. UPLIFT Study Investigators. A 4-year trial of tiotropium in chronic obstructive pulmonary disease. N Engl J Med 2008; 359: 1543-1554.

7 Peinado VI, Barbera JA, Ramirez J, et al. Endothelial dysfunction in pulmonary arteries of patients with mild COPD. Am J Physiol 1998; 274: L908-L913.

8 Barr RG, Mesia-Vela S, Austin JH, et al. Impaired flow-mediated dilation is associated with low pulmonary function and emphysema in ex-smokers: the Emphysema and Cancer Action Project (EMCAP) Study. Am J Respir Crit Care Med 2007; 176: 1200-1207.

9 Palange P, Testa U, Huertas A, et al. Circulating haemopoietic and endothelial progenitor cells are decreased in COPD. Eur Respir J 2006; 27: 529-541.

10 Vaidyula VR, Criner GJ, Grabianowski C, et al. Circulating tissue factor procoagulant activity is elevated in stable moderate to severe chronic obstructive pulmonary disease. Thromb Res 2009; 124: 259-261.

11 Kaczmarek P, Sladek K, Stepien E, et al. Fibrin clot properties are altered in patients with chronic obstructive pulmonary disease. Beneficial effects of simvastatin treatment. Thromb Haemost 2009; 102: 1176-1182.

12 Sabit R, Thomas P, Shale DJ, et al. The effects of hypoxia on markers of coagulation and systemic inflammation in patients with COPD. Chest 2010; 138: 47-51. 
Tillie-Leblond I, Marquette CH, Perez T, et al. Pulmonary embolism in patients with unexplained exacerbation of chronic obstructive pulmonary disease: prevalence and risk factors. Ann Intern Med 2006; 144: 390-396.

14 Gunen H, Gulbas G, In E, et al. Venous thromboemboli and exacerbations of COPD. Eur Respir J 2010; 35: 1243-1248.

15 Chaouat A, Naeije R, Weitzenblum E. Pulmonary hypertension in COPD. Eur Respir J 2008; 32: 1371-1385.

16 Chaouat A, Bugnet AS, Kadaoui N, et al. Severe pulmonary hypertension and chronic obstructive pulmonary disease. Am J Respir Crit Care Med 2005; 172: 189-194.

17 Jyothula S, Safdar Z. Update on pulmonary hypertension complicating chronic obstructive pulmonary disease. Int $J$ Chron Obstruct Pulmon Dis 2009; 4: 351-363.

18 Oswald-Mammosser M, Weitzenblum E, Quoix E, et al. Prognostic factors in COPD patients receiving long-term oxygen therapy. Importance of pulmonary artery pressure. Chest 1995; 107: 1193-1198.

19 Kessler R, Oswald-Mammosser M. Does lung volume reduction surgery compromise the pulmonary circulation? Am J Respir Crit Care Med 1999; 160: 1429-1430.

20 Fisher MR, Forfia PR, Chamera E, et al. Accuracy of Doppler echocardiography in the hemodynamic assessment of pulmonary hypertension. Am J Respir Crit Care Med 2009; 179: 615-621.

21 Weitzenblum E, Sautegeau A, Ehrhart M, et al. Long-term oxygen therapy can reverse the progression of pulmonary hypertension in patients with chronic obstructive pulmonary disease. Am Rev Respir Dis 1985; 131: 493-498.

22 Sin DD, Man SF. Chronic obstructive pulmonary disease as a risk factor for cardiovascular morbidity and mortality. Proc Am Thorac Soc 2005; 2: 8-11.

23 Hansson GK. Inflammation, atherosclerosis, and coronary artery disease. N Engl J Med 2005; 352: 1685-1695.

24 MacNee W, Maclay J, McAllister D. Cardiovascular injury and repair in chronic obstructive pulmonary disease. Proc Am Thorac Soc 2008; 5: 824-833.

25 Eickhoff P, Valipour A, Kiss D, et al. Determinants of systemic vascular function in patients with stable chronic obstructive pulmonary disease. Am J Respir Crit Care Med 2008; 178: 1211-1218.

26 Brekke PH, Omland T, Smith P, et al. Underdiagnosis of myocardial infarction in COPD. Cardiac Infarction Injury Score (CIIS) in patients hospitalized for COPD exacerbation. Respir Med 2008; 102: 1243-1247.

27 Sin DD, Man SF. Why are patients with chronic obstructive pulmonary disease at increased risk of cardiovascular diseases? The potential role of systemic inflammation in chronic obstructive pulmonary disease. Circulation 2003; 107: 1514-1519.

28 Calverley PMA, Andeson JA, Celli B, et al. Cardiovascular events in patients with COPD: TORCH study results. Thorax 2010; 65: 719-725.

29 Singh S, Loke YK, Furberg CD. Inhaled anticholinergics and risk of major adverse cardiovascular events in patients with chronic obstructive pulmonary disease: a systemic review. JAMA 2008; 301: 1227-1230.

30 Singh S, Loke YK, Enright PL, et al. Mortality associated with tiotropium mist inhaler in patients with chronic obstructive pulmonary disease: systematic review and meta-analysis of randomised controlled trials. BMJ $2011 ; 342$.

31 Le Jemtel TH, Padeletti M, Jelic S. Diagnostic and therapeutic challenges in patients with coexistent chronic obstructive disease and chronic heart failure. J Am Coll Cardiol 2007; 49: 171-180.

32 Freixa X, Portillo K, Paré C, et al. Echocardiographic abnormalities in patients with COPD at their first hospital admission. Eur Respir J 2013; 41: 784-791.

33 Rutten FH, Cramer MJ, Lammers JW, et al. Heart failure and chronic obstructive pulmonary disease: an ignored combination? Eur J Heart Fail 2006; 8: 707-711.

34 Sidney S, Sorel M, Quesenberry CP, et al. COPD and incident cardiovascular disease. Hospitalizations and mortality: Kaiser Permanente Medical Care Program. Chest 2005; 128: 2068-2075.

35 Garcia-Rodriguez LA, Wallander MA, Martin-Merino E, et al. Heart failure, myocardial infarction, lung cancer and death in COPD patients: a UK primary care study. Respir Med. 2010; 104: 1691-1699.

36 De Blois J, Simard S, Atar D, et al. COPD predicts mortality in HF: the Norwegian Heart Failure Registry. J Card Fail 2010; 16: 226-229.

37 Mascarenhas J, Lourenço P, Lopes R, et al. Chronic obstructive pulmonary disease in heart failure. Prevalence, therapeutic and prognostic implications. Am Heart J 2008; 155: 521-525.

38 Jabbour A, Macdonald PS, Keogh AM, et al. Differences between beta-blockers in patients with chronic heart failure and chronic obstructive pulmonary disease: a randomized crossover trial. I Am Coll Cardiol 2010; 55: $1780-1787$.

39 Ho KK, Pinsky JL, Kannel WB, et al. The epidemiology of heart failure: the Framingham Study. J Am Coll Cardiol 1993; 22: 6A-13A.

40 Flu WJ, van Gestel YR, van Kuijk JP, et al. Co-existence of COPD and left ventricular dysfunction in vascular surgery patients. Respir Med 2010; 104: 690-696.

41 Loganathan RS, Stover DE, Shi W, et al. Prevalence of COPD in women compared to men around the time of diagnosis of primary lung cancer. Chest 2006; 129: 1305-1312.

42 Young RP, Hopkins RJ, Christmas T, et al. COPD prevalence is increased in lung cancer, independent of age, sex and smoking history. Eur Respir J 2009; 34: 380-386.

43 Kiri VA, Soriano J, Visick G, et al. Recent trends in lung cancer and its association with COPD: an analysis using the UK GP Research Database. Prim Care Respir J 2010; 19: 57-61.

44 Mannino DM, Aguayo SM, Petty TL, et al. Low lung function and incident lung cancer in the United States: data From the First National Health and Nutrition Examination Survey follow-up. Arch Intern Med 2003; 163: 1475-1480.

45 de Torres JP, Marín JM, Casanova C, et al. Lung cancer in patients with COPD: incidence and predicting factors. Am J Respir Crit Care Med 2011; 184: 913-919.

46 Turner MC, Chen Y, Krewski D, et al. Chronic obstructive pulmonary disease is associated with lung cancer mortality in a prospective study of never smokers. Am J Respir Crit Care Med 2007; 176: 285-290.

47 Young RP, Hopkins RJ. How the genetics of lung cancer may overlap with COPD. Respirology 2011; 16: 1047-1055.

48 Cohen BH, Diamond EL, Graves CG, et al. A common familial component in lung cancer and chronic obstructive pulmonary disease. Lancet 1977; 2: 523-526.

49 Young RP, Hopkins RJ, Hay BA, et al. Lung cancer gene associated with COPD: triple whammy or possible confounding effect? Eur Respir J 2008; 32: 1158-1164. 
50 Schwartz AG, Ruckdeschel JC. Familial lung cancer: genetic susceptibility and relationship to chronic obstructive pulmonary disease. Am J Respir Crit Care Med 2006; 173: 16-22.

51 Young RP, Whittington CF, Hopkins RJ, et al. Chromosome 4q31 locus in COPD is also associated with lung cancer. Eur Respir J 2010; 36: 1375-1382.

52 Punturieri A, Szabo E, Croxton TL, et al. Lung cancer and chronic obstructive pulmonary disease: needs and opportunities for integrated research. J Natl Cancer Inst 2009; 101: 554-559.

53 Yao H, Rahman I. Current concepts on the role of inflammation in COPD and lung cancer. Curr Opin Pharmacol 2009; 9: 375-383.

54 The National Lung Screening Trial Research Team, Aberle DR, Adams AM. Reduced lung-cancer mortality with low-dose computed tomographic screening. N Engl J Med 2011; 365: 395-409.

55 Brunelli A, Charloux A, Bolliger CT, et al. ERS/ESTS clinical guidelines on fitness for radical therapy in lung cancer patients (surgery and chemo-radiotherapy). Eur Respir J 2009; 34: 17-41.

56 Wagena EJ, Van Der Meer RM, Ostelo RJ, et al. The efficacy of smoking cessation strategies in people with chronic obstructive pulmonary disease: results from a systematic review. Respir Med 2004; 98: 805-815.

57 Tashkin DP, Rennard S, Hays JT, et al. Effects of varenicline on smoking cessation in patients with mild to moderate COPD: a randomized controlled trial. Chest 2011; 139: 591-599.

58 Wu P, Wilson K, Dimoulas P, et al. Effectiveness of smoking cessation therapies: a systematic review and metaanalysis. BMC Public Health 2006; 6: 300.

59 Parimon T, Chien JW, Bryson CL, et al. Inhaled corticosteroids and risk of lung cancer among patients with chronic obstructive pulmonary disease. Am J Respir Crit Care Med 2007; 175: 712-719.

60 Kiri VA, Fabbri LM, Davis KJ, et al. Inhaled corticosteroids and risk of lung cancer among COPD patients who quit smoking. Respir Med 2009; 103: 85-90.

61 Yao R, Wang Y, Lemon WJ, et al. Budesonide exerts its chemopreventive efficacy during mouse lung tumorigenesis by modulating gene expressions. Oncogene 2004; 23: 7746-7752.

62 Sprague BL, Trentham-Dietz A, Klein BE, et al. Physical activity, white blood cell count, and lung cancer risk in a prospective cohort study. Cancer Epidemiol Biomarkers Prev 2008; 17: 2714-2722.

63 Regvat J, Zmitek A, Vegnuti M, et al. Anxiety and depression during hospital treatment of exacerbation of chronic obstructive pulmonary disease. J Int Med Res 2011; 39: 1028-1038.

64 Spitzer C, Gläser S, Grabe HJ, et al. Mental health problems, obstructive lung disease and lung function: findings from the general population. J Psychosom Res 2011; 71: 174-179.

65 Schneider C, Jick SS, Bothner U. COPD and the risk of depression. Chest 2010; 137: 341-347.

66 Kunik ME. Surprisingly high prevalence of anxiety and depression in chronic breathing disorders. Chest 2005; 127: 1205-1211.

67 Van Manen JG. Risk of depression in patients with chronic obstructive pulmonary disease and its determinants Thorax 2002; 57: 412-416.

68 Abrams TE, Vaughan-Sarrazin M, Vander Weg MW. Acute exacerbations of chronic obstructive pulmonary disease and the effect of existing psychiatric comorbidity on subsequent mortality. Psychosomatics 2011; 52: 441-449.

$69 \mathrm{Ng}$ TP, Niti M, Wan-Cheng T, et al. Depressive symptoms and chronic obstructive pulmonary disease. Arch Intern Med 2007; 167: 60-67.

70 Spitzer RL, Kroenke K, Williams JB. Validation and utility of a self-report version of the PRIME-MD: the PHQ primary care study; Primary Care Evaluation of Mental Disorders. Patient Health Questionnaire. JAMA 1999; 282: 1737-1744.

71 Koenig HG, Cohen HJ, Blazer DG, et al. Profile of depressive symptoms in younger and older medical inpatients with major depression. J Am Geriatr Soc 1993; 41: 1169-1176.

72 Yohannes AM, Roomi J, Baldwin RC, et al. Depression in elderly outpatients with disabling chronic obstructive pulmonary disease. Age Ageing 1998; 27: 155-160.

73 Zigmond AS, Snaith RP. The hospital anxiety and depression scale. Acta Pyschiatr Scand 1983; 67: 361-370.

74 Antonelli Incalzi R. Drawing impairment predicts mortality in severe COPD. Chest 2006; 128: 62-69.

75 Haute Autorité de Santé (France). Fiche de synthèse: comment prévenir les fractures dues à l'ostéoporose? www.plan-retraite.fr/prevenir_fractures_osteoporose.pdf Date last updated: May 2007. Date last accessed: February 15, 2013.

76 Graat-Verboom L, Wouters EFM, Smeenk FW, et al. Current status of research on osteoporosisin COPD: a systematic review. Eur Respir J 2009; 34: 209-218.

77 Scanlon PD, Connett JE, Wise RA, et al. Loss of bone density with inhaled triamcinolone in Lung Health Study II. Am J Respir Crit Care Med 2004; 170: 1302-1309.

78 Ferguson GT, Calverley PMA, Anderson JA, et al. Prevalence and progression of osteoporosis in patients with COPD. Results from the towards a revolution in COPD Health Study. Chest 2009; 136: 1456-1465.

79 Mineo TC, Ambrogi V, Mineo D, et al. Bone mineral density improvement after lung volume reduction surgery for severe emphysema. Chest 2005; 127: 1960-1966.

80 Maggi S, Siviero P, Gonnelli S, et al. EOLO Study Group. Osteoporosis risk in patients with chronic obstructive pulmonary disease: the EOLO study. J Clin Densitom 2009; 12: 345-352.

81 Ionescu AA, Schoon E. Osteoporosis in chronic obstructive pulmonary disease. Eur Respir J 2003; 22: Suppl. 46, $64 \mathrm{~s}-75 \mathrm{~s}$

82 Janssens W, Bouillon R, Claes B, et al. Vitamin D deficiency is highly prevalent in COPD and correlates with variants in the vitamin D-binding gene. Thorax 2010; 65: 215-220.

83 Barnes PJ. Chronic obstructive pulmonary disease: effects beyond the lungs. PLoS Med 2010; 7: e1000220.

84 Avenell A, Gillespie WJ, Gillespie LD, et al. Vitamin D and vitamin D analogues for preventing fractures associated with involutional and post-menopausal osteoporosis. Cochrane Database Syst Rev 2009; 2: CD000227.

85 Smith BJ, Laslett LL, Pile KD, et al. Randomized controlled trial of alendronate in airways disease and low bone mineral density. Chron Respir Dis 2004; 1: 131-137.

86 Grossman JM, Gordon R, Ranganath VK, et al. American College of Rheumatology 2010 recommendations for the prevention and treatment of glucocorticoid-induced osteoporosis. Arthritis Care Res (Hoboken) 2010; 62: $1515-1526$. 
492-501.

90 Cano N, Pichard C, Roth $\mathrm{H}$, et al. C reactive protein and body mass index predict outcome in end stage respiratory failure. Chest 2004; 126: 540-546.

91 Vestbo J, Prescott E, Almdal T, et al. Body mass, fat-free body mass, and prognosis in patients with chronic obstructive pulmonary disease from a random population sample: findings from the Copenhagen Cty Heart Study. Am J Respir Crit Care Med 2006; 173: 79-83.

92 Schols AM, Broekhuizen R, Weling-Scheepers CA, et al. Body composition and mortality in chronic obstructive pulmonary disease. Am J Clin Nutr 2005; 82: 53-59.

93 Landbo C, Prescott E, Lange $\mathrm{P}$, et al. Prognostic value of nutritional status in chronic obstructive pulmonary disease. Am J Respir Crit Care Med 1999; 160: 1856-1861.

94 Chailleux E, Laaban JP, Veale D. Prognostic value of nutritional depletion in patients with COPD treated by long term oxygen therapy: data from the ANTADIR observatory. Chest 2003; 123: 1460-1466.

95 Soler-Cataluna JJ, Sanchez-Sanchez L, Martinez Garcia M, et al. Mid arm muscle area is a better predictor of mortality than body mass index in COPD. Chest 2005; 128: 2108-2115.

96 Wilson DO, Rogers RM, Sanders MH, et al. Nutritional intervention in malnourished patients with emphysema. Am Rev Respir Dis 1986; 134: 672-677.

97 Eftymiou J, Fleming J, Gomes C, et al. The effect of supplementary oral nutrition in poorly nourished patients with chronic obstructive pulmonary disease. Am Rev Respir Dis 1988; 137: 1075-1082.

98 Fereira IM, Brooks D, Lacasse Y, et al. Nutritional support for individuals with COPD: a meta-analysis. Chest 2000; 117: $672-678$

99 Broekhuizen R, Wouters EF, Creutzberg EC, et al. Polyunsaturated fatty acids improve exercise capacity in chronic obstructive pulmonary disease. Thorax 2005; 60: 376-382.

100 Creutzberg EC, Wouters EF, Mostert R, et al. A role for anabolic steroids in the rehabilitation of patients with COPD? A double blind, placebo controlled, randomised trial. Chest 2003; 124: 1733-1742.

101 Weisberg J, Wanger J, Olson J, et al. Megestrol acetate stimulates weight gain and ventilation in underweight COPD patients. Chest 2002; 121: 1070-1078.

102 Schols AM. Nutritional rehabilitation: from pulmonary cachexia to sarcoPD. Eur Respir J 2009; 33: 949-950.

103 Pison CM, Cano NJ, Chérion C, et al. Multimodal nutritional rehabilitation improves clinical outcomes of malnourished patients with chronic respiratory failure: a randomised controlled trial. Thorax 2011; 66: 953-960.

104 Ora J, Laveneziana P, Ofir D, et al. Combined effects of obesity and chronic obstructive pulmonary disease on dyspnea and exercise tolerance. Am J Respir Crit Care Med 2009; 180: 964-971.

105 Jee S, Sull JW, Park J, et al. Body mass index and mortality in Korean men and women. N Engl J Med 2006; 355: 779-787.

106 Jordan JG, Mann JR. Obesity and mortality in persons with obstructive lung disease using data from the NHANES III. South Med J 2010; 103: 232-230.

107 World Health Organization. Definition, diagnosis and classification of diabetes mellitus and its complications. Report of a WHO consultation. Geneva, WHO, 1999.

108 International Diabetes Federation. The IDF consensus. Worldwide definition of the metabolic syndrome. www.idf.org

109 Alberti KG, Zimmet P, Shaw J. Metabolic syndrome: a new world wide definition: a consensus statement from the IDF. Diabetic Medicine 2006; 23: 469-480.

110 Mannino DM, Thorn D, Swensen A, et al. Prevalence and outcomes of diabetes, hypertension and cardiovascular disease in COPD. Eur Respir J 2008; 32: 962-969.

111 Feary JR, Rodrigues LC, Smith CJ, et al. Prevalence of major comorbidities in subjects with COPD and incidence of myocardial infarction and stroke: a comprehensive analysis using data from primary care. Thorax 2010; 65: 956-962.

112 Cazzola M, Bettoncelli G, Sessa E, et al. Prevalence of comorbidities in patients with COPD. Respiration 2010; 80: $112-119$.

113 Ghanassia E, Jaussent A, Picot MC, et al. [Prévalence de l'insulinorésistance et du syndrome métabolique chez le sujet BPCO]. Rev Mal Respir 2006; 23, 4: 393.

114 Watz H, Waschki B, Kirsten A, et al. The metabolic syndrome in patients with chronic bronchitis and COPD. Chest 2009; 136, 4: 1039-1046.

115 Song Y, Klevak A, Manson JE, et al. Asthma, chronic obstructive pulmonary disease, and type 2 diabetes in the Women's Health Study. Diabetes Res Clin Pract 2010; 90: 365-371.

116 Ehrlich SF, Quesenberry CP Jr, Van Den Eeden SK, et al. Patients diagnosed with diabetes are at increased risk for asthma, COPD, pulmonary fibrosis and pneumonia but not lung cancer. Diabetes care 2010; 33, 1: 55-60.

117 Seshasai SR, Kaptoge S, Thompson A, et al. Diabetes mellitus, fasting glucose and risk of cause specific death. N Engl J Med 2011; 364: 829-841.

118 Baker EH, Janaway CH, Philips BJ, et al. Hyperglycemia is associated with poor outcomes in patients admitted to hospital with acute exacerbations of COPD. Thorax 2006; 61: 284-289.

119 Parappil A, Depczynski B, Collett P, et al. Effect of comorbid diabetes on length of stay and risk of death in patients with acute exacerbations of COPD. Respirology 2010; 15: 918-922.

120 Manson JE, Ajani UA, Liu S, et al. A prospective study of cigarette smoking and the incidence of diabetes mellitus among US male physicians. Am J Med 2000; 109: 538-542.

121 Shoelson SE, Lee J, Goldfine AB. Inflammation and insulin resistance. J Clin Invest 2006; 116: 1793-1801.

122 Pradhan A. Obesity, metabolic syndrome, and type 2 diabetes: inflammatory basis of glucose metabolic disorders. Nutr Rev 2007; 65: S152-S156.

123 Fabbri LM, Luppi F, Beghé B, et al. Complex chronic comorbidities of COPD. Eur Respir J 2008; 31: $204-212$.

124 Tkacova R. Systemic inflammation in chronic obstructive pulmonary disease: may adipose tissue play a role? Review of the literature and future perspectives. Mediators Inflamm 2010; 2010: 585989. 
125 Walter RE, Beiser A, Givelber RJ, et al. Association between glycemic state and lung function: the Framingham Heart Study. Am J Respir Crit Care Med 2003; 167: 911-916.

126 Yeh HC, Punjabi NM, Wang NY, et al. Cross-sectional and prospective study of lung function in adults with type 2 diabetes: the Atherosclerosis Risk in Communities (ARIC) study. Diabetes Care 2008; 31: 741-746.

127 van den Borst B, Gosker HR, Zeegers MP, et al. Pulmonary function in diabetes: a metaanalysis. Chest 2010; 138, 2: 393-406.

128 Leone N, Courbon D, Thomas F, et al. Lung function impairment and metabolic syndrome: the critical role of abdominal obesity. Am J Respir Crit Care Med 2009; 179: 509-516.

129 Funakoshi Y, Omori H, Mihara S, et al. Association between airflow obstruction and the metabolic syndrome or its components in Japanese men. Intern Med 2010; 49: 2093-2099.

130 Lam KB, Jordan RE, Jiang CQ, et al. Airflow obstruction and metabolic syndrome: the Guangzhou Biobank Cohort Study. Eur Respir J 2010; 35: 317-323.

131 Cuvelier A. [Pathologies extra-thoraciques au cours de la BPCO]. Rev Mal Respir 2006; 23: 25-31.

132 Burt MG, Roberts GW, Aguilar-Loza NR, et al. Continuous monitoring of circadian glycemic patterns in patients receiving prednisolone for COPD. J Clin Endocrinol Metab 2011; 96: 1789-1796.

133 Suissa S, Kezouh A, Ernst P. Inhaled corticosteroids and the risks of diabetes onset and progression. Am J Med 2010; 123: 1001-1006.

134 Lemyze M, Baudry JF, Collet F, et al. Life threatening lactic acidosis. BMJ 2010; 340: c857.

135 Bruijstens LA, van Luin M, Buscher-Jungerhans PMM, et al. Reality of severe metformin induced lactic acidosis in the absence of chronic renal impairment. J Med 2008; 66, 5: 185-190.

136 Jones GC, Macklin JP, Alexander WD. Contraindications to the use of metformin: evidence suggests that it is time to amend the list. BMJ 2003; 326: 4-5.

137 Sulkin TV, Bosman D, Krentz AJ. Contraindications to metformin therapy in patients with NIDDM. Diabetes Care 1997; 20: 925-928.

138 Holstein A, Nahrwold D, Hinze S, et al. Contraindications to metformin therapy are largely disregarded. Diabet Med 1999; V16: 692-696.

139 Rachmani R, Slavachevski I, Levi Z, et al. Metformin in patients with type 2 diabetes mellitus: reconsideration of traditional contraindications. Eur J Int Med 2002; 13: 428-433.

140 Van Berlo-Van de Laar IRF, Vermeij CG, Doorenbos CJ. Metformin associated lactic acidosis: incidence and clinical correlation with metformin serum concentration measurements. J Clin Pharm Ther 2011; 36: 376-382.

141 Stades AME, Heikens JT, Erkelens DW, et al. Metformin and lactic acidosis: cause or coincidence? A review of case reports. J Intern Med 2004; 255: 179-187.

142 Scale Y, Harvey JN. Diabetes, metformin and lactic acidosis. Clin Endocrinol (Oxf) 2011; 74: 191-196.

143 Young RP, Hopkins R, Eaton TE. Pharmacological actions of statins: potential utility in COPD. Eur Respir J 2009; 114: 222-232.

144 Barnes PJ, Celli BR. Systemic manifestations and comorbidities of COPD. Eur Respir J 2009; 33: 1165-1185.

145 Mancini GB, Etminan M, Zhang B, et al. Reduction of morbidity and mortality by statins, angiotensin-converting enzyme inhibitors, and angiotensin receptor blockers in patients with chronic obstructive pulmonary disease. J Am Coll Cardiol 2006; 47: 2554-2560.

146 Rutten FH, Zuithoff NP, Hak E, et al. Beta-blockers may reduce mortality and risk of exacerbations in patients with chronic obstructive pulmonary disease. Arch Intern Med 2010; 170: 880-887.

147 Cormick W, Olson LG, Hensley MJ, et al. Nocturnal hypoxaemia and quality of sleep in patients with chronic obstructive lung disease. Thorax 1986; 41: 846-854.

148 Klink ME, Dodge R, Quan SF. The relation of sleep complaints to respiratory symptoms in a general population. Chest 1994; 105: 151-154.

149 Dodge R, Cline MG, Quan SF. The natural history of insomnia and its relationship to respiratory symptoms. Arch Intern Med 1995; 155: 1797-1800.

150 Sanders MH, Newman AB, Haggerty CL, et al. Sleep and sleep-disordered breathing in adults with predominantly mild obstructive airway disease. Am J Respir Crit Care Med 2003; 167: 7-14.

151 Krachman S, Minai OA, Scharf SM. Sleep abnormalities and treatment in emphysema. Proc Am Thorac Soc 2008; 5 : 536-542.

152 Krachman SL, Chatila W, Martin UJ, et al. Physiologic correlates of sleep quality in severe emphysema. COPD 2011; 8: $182-188$.

153 Valipour A, Lavie P, Lothaller $\mathrm{H}$, et al. Sleep profile and symptoms of sleep disorders in patients with stable mild to moderate chronic obstructive pulmonary disease. Sleep Med 2011; 12: 367-372.

154 Budhiraja R, Roth T, Hudgel DW, et al. Prevalence and polysomnographic correlates of insomnia comorbid with medical disorders. Sleep 2011; 34: 859-867.

155 Kwon JS, Wolfe LF, Lu BS, et al. Hyperinflation is associated with lower sleep efficiency in COPD with co-existent obstructive sleep apnea. COPD 2009; 6: 441-445.

156 Krachman SL, Chatila W, Martin UJ, et al. National Emphysema Treatment Trial Research Group. Effects of lung volume reduction surgery on sleep quality and nocturnal gas exchange in patients with severe emphysema. Chest 2005; 128: 3221-3228.

157 Lewis CA, Fergusson W, Eaton T, et al. Isolated nocturnal desaturation in COPD: prevalence and impact on quality of life and sleep. Thorax 2009; 64: 133-138.

158 Lo Coco D, Mattaliano A, Lo Coco A, et al. Increased frequency of restless legs syndrome in chronic obstructive pulmonary disease patients. Sleep Med 2009; 10: 572-576.

159 Scharf SM, Maimon N, Simon-Tuval T, et al. Sleep quality predicts quality of life in chronic obstructive pulmonary disease. Int J Chron Obstruct Pulmon Dis 2010; 6: 1-12.

160 Chaouat A, Weitzenblum E, Kessler R, et al. A randomized trial of nocturnal oxygen therapy in chronic obstructive pulmonary disease patients. Eur Respir J 1999; 14: 1002-1008.

161 Fletcher EC, Luckett RA, Goodnight-White S, et al. A double-blind trial of nocturnal supplemental oxygen for sleep desaturation in patients with chronic obstructive pulmonary disease and a daytime $\mathrm{Pa}_{\mathrm{a}} \mathrm{O}_{2}$ above $60 \mathrm{mmHg}$. Am Rev Respir Dis 1992; 145: 1070-1076. 
162 McNicholas WT, Calverley PM, Lee A, et al. Tiotropium Sleep Study in COPD Investigators. Long-acting inhaled anticholinergic therapy improves sleeping oxygen saturation in COPD. Eur Respir J 2004; 23: 825-831.

163 Ryan S, Doherty LS, Rock C, et al. Effects of salmeterol on sleeping oxygen saturation in chronic obstructive pulmonary disease. Respiration 2010; 79: 475-481.

164 Donohue JF, Fogarty C, Lötvall J, et al. INHANCE Study Investigators. Once-daily bronchodilators for chronic obstructive pulmonary disease: indacaterol versus tiotropium. Am J Respir Crit Care Med 2010; 182: 155-162.

165 Kornmann O, Dahl R, Centanni S, et al. INLIGHT-2 study investigators. Once-daily indacaterol versus twice-daily salmeterol for COPD: a placebo-controlled comparison. Eur Respir J 2011; 37: 273-279.

166 Wijkstra PJ, Lacasse Y, Guyatt GH, et al. A meta-analysis of nocturnal noninvasive positive pressure ventilation in patients with stable COPD. Chest 2003; 124: 337-343.

167 Clini E, Sturani C, Rossi A, et al. Rehabilitation and Chronic Care Study Group, Italian Association of Hospital Pulmonologists (AIPO). The Italian multicentre study on noninvasive ventilation in chronic obstructive pulmonary disease patients. Eur Respir J 2002; 20: 529-538.

168 McEvoy RD, Pierce RJ, Hillman D, et al. Australian trial of non-invasive Ventilation in Chronic Airflow Limitation (AVCAL) Study Group. Nocturnal non-invasive nasal ventilation in stable hypercapnic COPD: a randomised controlled trial. Thorax 2009; 64: 561-566.

169 Crisafulli E, Manni G, Kidonias M, et al. Subjective sleep quality during average volume assured pressure support (AVAPS) ventilation in patients with hypercapnic COPD: a physiological pilot study. Lung 2009; 187: 299-305.

170 Scharf SM, Maimon N, Simon-Tuval T, et al. Sleep quality predicts quality of life in chronic obstructive pulmonary disease. Int J Chron Obstruct Pulmon Dis 2010; 6: 1-12.

171 Nunes DM, Mota RM, de Pontes Neto OL, et al. Impaired sleep reduces quality of life in chronic obstructive pulmonary disease. Lung 2009; 187: 159-163.

172 Roth T. Hypnotic use for insomnia management in chronic obstructive pulmonary disease. Sleep Med 2009; 10: 19-25.

173 Stege G, Vos PJ, van den Elshout FJ, et al. Sleep, hypnotics and chronic obstructive pulmonary disease. Respir Med 2008; 102: 801-814.

174 Stege G, Heijdra YF, van den Elshout FJ, et al. Temazepam $10 \mathrm{mg}$ does not affect breathing and gas exchange in patients with severe normocapnic COPD. Respir Med 2010; 104: 518-524.

175 Bednarek M, Plywaczewski R, Jonczak L, et al. There is no relationship between chronic obstructive pulmonary disease and obstructive sleep apnea syndrome: a population study. Respiration 2005; 72: 142-149.

176 Chaouat A, Weitzenblum E, Krieger J, et al. Association of chronic obstructive pulmonary disease and sleep apnea syndrome. Am J Respir Crit Care Med 1995; 151: 82-86.

177 Hawryłkiewicz I, Sliwiński P, Górecka D, et al. Pulmonary haemodynamics in patients with OSAS or an overlap syndrome. Monaldi Arch Chest Dis 2004; 61: 148-152.

178 Marin JM, Soriano JB, Carrizo SJ, et al. Outcomes in patients with chronic obstructive pulmonary disease and obstructive sleep apnea: the overlap syndrome. Am J Respir Crit Care Med 2010; 182: 325-331.

179 McNicholas WT. Chronic obstructive pulmonary disease and obstructive sleep apnea: overlaps in pathophysiology, systemic inflammation, and cardiovascular disease. Am J Respir Crit Care Med 2009; 180: 692-700.

180 Machado MC, Vollmer WM, Togeiro SM, et al. CPAP and survival in moderate-to-severe obstructive sleep apnoea syndrome and hypoxaemic COPD. Eur Respir J 2010; 35: 132-137.

181 Weitzenblum E, Chaouat A, Kessler R, et al. Overlap syndrome: obstructive sleep apnea in patients with chronic obstructive pulmonary disease. Proc Am Thorac Soc 2008; 5: 237-241.

182 World Health Organization. Iron deficiency anemia. assessment, prevention, and control. A guide for programme managers. Geneva, WHO, 2001.

183 Cote C, Zilberberg MD, Mody SH, et al. Haemoglobin level and its clinical impact in a cohort of patients with COPD. Eur Respir J 2007; 29: 923-929.

184 Chambellan A, Chailleux E, Similowski T. Prognostic value of the hematocrit in patients with severe COPD receiving long-term oxygen therapy. Chest 2005; 128: 1201-1208.

185 John M, Lange A, Hoernig S, et al. Prevalence of anemia in chronic obstructive pulmonary disease: comparison to other chronic diseases. Int J Cardiol 2006; 111: 365-370.

186 Weiss G, Goodnough LT. Anemia of chronic disease. N Engl J Med 2005; 352: 1011-1023.

187 John M, Hoernig S, Doehner W, et al. Anemia and inflammation in COPD. Chest 2005; 127: 825-829.

188 Markoulaki D, Kostikas K, Papatheodorou G, et al. Hemoglobin, erythropoietin and systemic inflammation in exacerbations of chronic obstructive pulmonary disease. Eur J Intern Med 2011; 22: 103-107.

189 Tanner H, Moschovitis G, Kuster GM, et al. The prevalence of anemia in chronic heart failure. Int J Cardiol 2002; 86: 115-121.

190 Cromie N, Lee C, Struthers AD. Anaemia in chronic heart failure: what is its frequency in the UK and its underlying causes? Heart 2002; 87: 377-378.

191 Ezekowitz JA, McAlister FA, Armstrong PW. Anemia is common in heart failure and is associated with poor outcomes: insights from a cohort of 12065 patients with new-onset heart failure. Circulation 2003; 107: 223-225.

192 Okonko DO, Anker SD. Anemia in chronic heart failure: pathogenetic mechanisms. J Card Fail 2004; 10: Suppl. 1, S5-S9.

193 Krishnan G, Grant BJ, Muti PC, et al. Association between anemia and quality of life in a population sample of individuals with chronic obstructive pulmonary disease. BMC Pulm Med 2006; 6: 23.

194 Schonhofer B, Wenzel M, Geibel M, et al. Blood transfusion and lung function in chronically anemic patients with severe chronic obstructive pulmonary disease. Crit Care Med 1998; 26: 1824-1828.

195 van der Meer P, Groenveld HF, Januzzi JL Jr, et al. Erythropoietin treatment in patients with chronic heart failure: a meta-analysis. Heart 2009; 95: 1309-1314.

196 Washko GR, Hunninghake GM, Fernandez IE, et al. COPDGene Investigators. Lung volumes and emphysema in smokers with interstitial lung abnormalities. N Engl J Med 2011; 364: 897-906.

197 Cottin V, Nunes H, Brillet PY, et al. Combined pulmonary fibrosis and emphysema: a distinct underrecognised entity. Eur Respir J 2005; 26: 586-593.

198 Cottin V. Pragmatic prognostic approach of rheumatoid arthritis-associated interstitial lung disease. Eur Respir J 2010; 35: 1206-1208. 

emphysema. Respirology 2010; 15: 265-271.

200 Agusti A, Calverley PM, Celli B, et al. Evaluation of COPD Longitudinally to Identify Predictive Surrogate Endpoints (ECLIPSE) investigators. Characterisation of COPD heterogeneity in the ECLIPSE cohort. Respir Res 2010; 11: 122 .

201 Burgel PR, Roche N, Paillasseur JL, et al. INITIATIVES BPCO Scientific Committee. Clinical COPD phenotypes identified by cluster analysis: validation with mortality. Eur Respir J 2012; 40: 495-496.

202 Wedzicha JA, Seemungal TA, MacCallum PK, et al. Acute exacerbations of chronic obstructive pulmonary disease are accompanied by elevations of plasma fibrinogen and serum IL-6 levels. Thromb Haemost 2000; 84: $210-215$.

203 Drost EM, Skwarski KM, Sauleda J, et al. Oxidative stress and airway inflammation in severe exacerbations of COPD. Thorax 2005; 60: 293-300.

204 Donaldson GC, Hurst JR, Smith CJ, et al. Increased risk of myocardial infarction and stroke following exacerbation of COPD. Chest 2010; 137: 1091-1097.

205 Kiyokawa H, Muro S, Oguma T, et al. Impact of COPD exacerbations on osteoporosis assessed by chest CT scan. COPD 2012; 9: 235-242.

206 Vermeeren MA, Schols AM, Wouters EF. Effects of an acute exacerbation on nutritional and metabolic profile of patients with COPD. Eur Respir J 1997; 10: 2264-2269.

207 Zvezdin B, Milutinov S, Kojicic M, et al. A post mortem analysis of major causes of early death in patients hospitalized with COPD exacerbation. Chest 2009; 136: 376-380.

208 Dahlén I, Janson C. Anxiety and depression are related to the outcome of emergency treatment in patients with obstructive pulmonary disease. Chest 2002; 122: 1633-1637.

209 Gudmundsson G, Gislason T, Janson C, et al. Risk factors for rehospitalisation in COPD: role of health status, anxiety and depression. Eur Respir J 2005; 26: 414-419.

210 Papaioannou AI, Bartziokas K, Tsikrika S, et al. The impact of depressive symptoms on recovery and outcome of hospitalised COPD exacerbations. Eur Respir J 2013; 41: 815-823.

211 Küpeli E, Ulubay G, Ulasli SS, et al. Metabolic syndrome is associated with increased risk of acute exacerbation of COPD: a preliminary study. Endocrine 2010; 38: 76-82. 